\title{
Composição arquitetônica e qualidade estética
}

\author{
Architectural composition and aesthetics quality
}

\section{Antônio Tarcísio da Luz Reis Camila Damiani Biavatti Maria Lourdes Pereira}

\section{Resumo}

$\mathbf{E}$

ste artigo analisa a relação entre composição arquitetônica e qualidade estética, considerando os pressupostos da estética filosófica e da estética empírica, e o papel da estética formal e da estética simbólica em explicar tal relação. Edificações históricas e contemporâneas com distintos níveis de ordem e estímulo visual são avaliadas por pessoas com distintos níveis e tipos de formação acadêmica e são identificadas as razões para tais avaliações. A coleta de dados inclui levantamentos de arquivo, levantamentos físicos, questionários e entrevistas realizados com 60 arquitetos, 60 não arquitetos com curso universitário e 60 pessoas sem curso universitário, que avaliaram imagens de três edificações históricas e três edificações contemporâneas, categorizadas conforme segue: ordem e estímulo visual; ordem e pouco estímulo visual; e desordem. As respostas dos questionários foram analisadas através de testes estatísticos não paramétricos, tais como Kruskal-Wallis e Kendall W. As informações fornecidas através das entrevistas foram analisadas por meio de suas frequências e significados. Os resultados indicam, que, embora os arquitetos tendam a valorizar a existência de ordem na composição arquitetônica e os não arquitetos a valorizar a existência de estímulo visual, quando ambos estão presentes a composição arquitetônica tende a ser avaliada positivamente.

Palavras-chave: Composição arquitetônica. Qualidade estética. Avaliação estética. Estética empírica. Estética formal. Estética simbólica.

Antônio Tarcísio da Luz Reis Universidade Federal do Rio Grande Porto Alegre - RS - Brasil

Camila Damiani Biavatti Universidade Federal do Rio Grande Porto Alegre - RS - Brasil

Maria Lourdes Pereira Universidade Federal do Rio Grande Porto Alegre - RS - Brasil

Recebido em 25/02/13 Aceito em 28/12/13

\begin{abstract}
The article analyses the relationship between architectural composition and aesthetic quality, considering the assumptions of philosophical aesthetics and empirical aesthetics, and the role of formal and symbolic aesthetics to explain this relationship. Historic and contemporary buildings with different levels of order and visual stimuli are evaluated by people with different levels and types of college education, and the reasons for such assessments are identified. Data collection includes archival records, physical measurements, and questionnaires and interviews conducted with 60 architects, 60 non-architect college graduates and 60 non-college graduates, in order to evaluate images of three historic buildings and three contemporary buildings, classified as: order and visual stimuli; order and low visual stimuli; and disorder. The responses to the questionnaires were analysed using nonparametric statistical tests such as Kruskal-Wallis and Kendall $W$. The information provided in the interviews was analysed through its frequency and meanings. The results indicate that while architects tended to place great value on the existence of order in an architectural composition and non-architects tended to place great value on the existence of visual stimulus, when both are present, the architectural composition tends to be positively evaluated.
\end{abstract}

Keywords: Architectural composition. Aesthetics quality. Aesthetics evaluation. Empirical aesthetics. Formal aesthetics. Symbolic aesthetics. 


\section{Introdução}

A ideia de composição arquitetônica remete à relação entre os elementos que fazem parte de uma edificação. Assim, como em uma composição musical, a existência de uma relação adequada entre os elementos pressupõe a existência de uma composição arquitetônica adequada ou satisfatória para quem a percebe. Conforme mencionado por Hasse e Weber (2010, p. 1), “Composição arquitetônica pode ser vista como a arte de balancear partes arquitetônicas individuais dentro de todo um conjunto de uma edificação [...]". Logo, a qualidade estética de uma composição arquitetônica pode ser determinada pela percepção visual e consequente avaliação por parte de um observador. $\mathrm{O}$ aspecto visual é um dos itens considerados na análise de impacto ambiental de projetos e é, com frequência, utilizado como a base para iniciativas de políticas públicas nos Estados Unidos, assim como de comitês de avaliação arquitetônica e associações de melhorias de centros urbanos. Mais de $90 \%$ das grandes cidades americanas utilizam a análise de impacto visual aplicada a edificações individuais e, adicionalmente, a Suprema Corte dos Estados Unidos menciona o critério estético como suficiente para uma base adequada para desenvolvimento. Além disso, em 30 estados americanos as cortes determinam que as considerações estéticas são suficientes para estabelecer regulamentações. Especificamente, a Lei de Proteção Ambiental Nacional de $1969^{1}$ (National Environmental Protection Act), que determina uma avaliação cuidadosa dos efeitos de grandes projetos sobre o ambiente, requer consideração dos impactos visuais. Ainda, as cortes americanas sustentam que a beleza ambiental é de legítimo interesse público e deve estar baseada nas preferências do público, e não no gosto pessoal de funcionários do governo (REIS; LAY, 2003, 2006; SANOFF, 1991; STAMPS, 2000).

Além da importância da dimensão visual da estética atestada pelas cortes americanas, vários estudos têm mencionado a importância de uma aparência atraente para um ambiente satisfatório e com bom desempenho para seus usuários (COOPER MARCUS; SARKISSIAN, 1986; ISAACS， 2000; JACOBS, 2000; KAPLAN; KAPLAN; RYAN, 1998; NASAR, 1997; REIS; LAY, 2003; STAMPS, 2000; WHYTE, 1990). Especificamente, a qualidade estética de conjuntos habitacionais tem sido um fator fortemente conectado à satisfação dos residentes com o ambiente habitacional e confirmado como

\footnotetext{
${ }^{1}$ Disponível em: <http://www.epw.senate.gov/nepa69.pdf>.
}

importante também no contexto brasileiro, além, por exemplo, de países europeus (REIS, 1992; REIS; LAY 2003). A importância da estética do ambiente construído é também revelada pelo fato de que sua qualidade estética pode influenciar, além das atitudes e bem-estar das pessoas, seus comportamentos, já que somos atraídos a ir e a voltar a ambientes esteticamente atraentes e a evitar ou a se recusar a ir a locais esteticamente desagradáveis (NASAR, 1992a, 1998). Nasar (1992a, p. xxi, xxiii) salienta que:

\section{Berlyne $(1971)^{2}$ tem demonstrado que o caráter visual do estímulo influência comportamentos tais como atenção, tempo de observação, ou escolha [... e que depois disto] pesquisadores tem encontrado evidência de efeitos sobre o comportamento espacial [...].}

Uma vez que fica evidenciada a importância da qualidade estética de um ambiente ou da composição arquitetônica de uma edificação, podese verificar a possibilidade de compreensão de avaliações estéticas positivas ou negativas a partir das características de tais composições. Tal possibilidade está contemplada na abordagem da estética empírica que envolve os processos de percepção e cognição, e considera que é possível haver reações estéticas idênticas ou similares, por parte de diferentes pessoas, para determinada composição arquitetônica, possibilitando a concepção da ideia de que a beleza está mais no objeto percebido do que nos olhos de quem vê, ao contrário da estética filosófica que pressupõe que "a beleza está nos olhos de quem vê" e, logo, descarta as avaliações estéticas, conforme já salientado em outros textos (por exemplo, Reis, Biavatti e Pereira, 2011)

Assim, enquanto a abordagem filosófica trata de teorias normativas, a abordagem empírica trata da teoria positiva. A teoria normativa consiste em prescrições para ação, normas, manifestos, princípios sobre o que é, por exemplo, boa arquitetura, com base numa posição ideológica ou visão de mundo, e logo, sem que tenham sido testados ou que exista a necessidade de testá-los (LANG, 1987). Por sua vez, a teoria positiva consiste em afirmações (daí o nome "positiva") que podem ser testadas por meio de métodos científicos, tendo como objetivo procurar explicações e ter poder de previsão. Assim, a abordagem empírica utiliza-se da teoria positiva para analisar a experiência estética através de

\footnotetext{
${ }^{2}$ BERLYNE, D. E. Aesthetics and Psychobiology. New York: Appleton-Century-Crofts, 1971.
} 
métodos científicos (LANG, 1987). Desse modo, na abordagem da estética empírica faz sentido realizar avaliações estéticas com o objetivo não somente de identificar o resultado de tais avaliações e possíveis tendências e consensos estéticos, mas também as razões destas avaliações, para que tais resultados possam ser incorporados em composições arquitetônicas de maneira a qualificá-las esteticamente. A área da estética empírica tem-se desenvolvido a partir do final do século XIX, com os estudos psicológicos da experiência estética por Gustav Fechner em 1876 (LANG, 1987) e tem-se mantido ao longo do século XX e deste início de século através de pesquisas e resultados apresentados, por exemplo: em congressos internacionais tais como a EDRA (Environmental Design Research Association), IAPS (International Association for PeopleEnvironment Studies), e o congresso específico sobre estética empírica promovido pela International Association of Empirical Aesthetics; e em congressos nacionais tais como o Encontro Nacional de Tecnologia do Ambiente Construído (Entac) e o Simpósio Brasileiro de Qualidade do Projeto no Ambiente Construído (SBQP). Livros específicos sobre a estética empírica têm sido publicados, tais como: Environmental aesthetics: theory, research, and applications (NASAR, 1992a); On the aesthetics of architecture, a psychological approach to the structure and the order of perceived architectural space (WEBER, 1995); Environmental aesthetics: ideas, politics and planning (PORTEOUS, 1996). Adicionalmente, periódicos internacionais (por exemplo, Journal of Architectural and Planning Research e Environment and Behaviour), na área de estudos que trata da relação entre o ambiente e seus usuários (ambiente/comportamento ou percepção ambiental), têm contemplado a publicação de estudos envolvendo a estética empírica, assim como a própria revista Ambiente Construído o tem feito.

Ainda, conforme já mencionado em estudos anteriores (por exemplo, Reis, Biavatti e Pereira, 2011), a estética empírica pode ser categorizada em estética formal, que trata das características físicas da composição arquitetônica, de sua estrutura formal e de sua percepção visual, e em estética simbólica, que trata do conteúdo ou significado da estrutura, das associações simbólicas proporcionadas por tais características, pelo uso da edificação e/ou por sua história, como resultado do processo de cognição (LANG, 1987). Assim, a qualidade estética de uma composição arquitetônica poderia estar relacionada a suas características formais e/ou a suas associações simbólicas. As características formais são percebidas, através do estímulo visual gerado por elas, antes de o indivíduo se tornar consciente do significado e do valor de tais características da composição arquitetônica e realizar tais associações, isto é, antes do processo de cognição (REIS; LAY, 2006; WEBER, 1995). Logo, a percepção visual dos elementos formais de uma composição arquitetônica depende das relações internas entre tais elementos, enquanto as associações dependem das relações externas da composição com aspectos do mundo exterior (AMEDEO, 1999). Essas relações internas tendem a ser percebidas de maneira similar por pessoas com características culturais distintas, conforme já revelado pela Teoria da Gestalt e explicado pelo fato de o processo de percepção visual ser uma consequência de processos fisiológicos (PRAK, 1985; WEBER, 1995). Assim, a existência da ideia de ordem (considerada como uma necessidade fisiológica e psicológica humana, estando relacionada a um funcionamento orgânico adequado) em distintas composições arquitetônicas, tenderia a ser percebida e avaliada positivamente por diferentes pessoas (NASAR, 1998; VON MEISS, 1993; WEBER, 1995). Herzog (1992) menciona que edificações que parecem mais ordenadas ou coerentes são preferidas, enquanto Megahed e Gabr (2010, p. 34) citam que:

\section{As características de ordem, muito provavelmente, produzem sentimentos positivos enquanto ambiguidade, repetição indevida, e imperfeição produzem sentimentos negativos [...].}

O próprio conceito de composição arquitetônica remete à ideia de equilíbrio, de organização, de ordem. Contudo, seria a existência de ordem, independentemente do nível de estímulo visual, uma condição suficiente para que uma composição arquitetônica fosse percebida por diferentes pessoas como esteticamente qualificada? O nível de estímulo visual estaria relacionado ao nível de contraste entre os elementos arquitetônicos e ao nível de complexidade de uma composição arquitetônica (por exemplo, Reis, 2002b). O aumento da complexidade de tal composição aumentaria a preferência estética por ela, mantido um nível adequado de coerência e legibilidade (HERZOG; SHIER, 2000), isto é, um nível adequado de ordem na composição.

Por outro lado, as relações externas que geram as associações tendem a ser afetadas pelas características culturais das pessoas, assim como por outras características, incluindo experiências prévias, valores e memória (WEBER, 1995), e, logo, tais associações simbólicas estariam mais sujeitas a variações. Nesse sentido, o valor 
histórico de uma edificação seria uma associação estabelecida com base no valor que tal edificação teria em função de sua história, o que pressupõe algum conhecimento acerca dessa história por parte de quem estabelece tal associação. Contudo, edificações mais antigas ou históricas poderiam ser avaliadas positivamente não em função de seu valor histórico, ou de alguma outra associação com o passado, mas sim devido a suas características formais, normalmente com a presença de ordem e alguma variedade gerando certo estímulo visual (NASAR, 1998). Estudos mencionados por Herzog e Shier (2000) demonstram que a relação entre a idade da edificação e a preferência depende do nível de manutenção da edificação e que, quando esta é controlada (condições similares de manutenção), as edificações mais antigas são geralmente preferidas em relação às edificações modernas. Entretanto, em seus estudos mais recentes, Herzog e Shier (2000, p. 571) salientam que "[...] parece que para edificações igualmente bem mantidas e com alta complexidade a idade não tem influência sobre a preferência [...]". Contudo, os autores reforçam que "[...] os resultados necessitam claramente ser replicados antes que suas implicações sejam consideradas seriamente [...]" (HERZOG; SHIER, 2000, p. 571).

Por sua vez, o significado de uma edificação em função de seu nível da familiaridade também pode afetar sua avaliação estética. Por exemplo, em estudo realizado por Herzog, Kaplan e kaplan (1976), uma maior familiaridade (definida como o quanto a edificação era conhecida do avaliador) com edificações contemporâneas parece ter diminuído a preferência por elas, enquanto uma maior familiaridade com edificações mais antigas tendia a aumentar a preferência por estas, sugerindo uma interação significativa entre familiaridade e conteúdo da cena (tipo de objeto ou edificação). Como decorrência, Herzog, Kaplan e Kaplan (1976, p. 642) enfatizavam que "Seria muito interessante estudar o que é que faz certos desenhos ganharem em preferência na medida em que se tornam familiares, enquanto para outros a preferência diminui quando a novidade inicial começa a sair de moda". Por outro lado, alguns estudos transculturais indicam que a preferência de distintos grupos por diferentes paisagens naturais tem sido substancialmente explicada pela familiaridade, com o aumento desta provocando um aumento na preferência (FALK; BALLING, 2010).

Ainda, o tipo e o nível de formação acadêmica poderiam afetar as avaliações estéticas, como ilustra um estudo sobre as fachadas de edificações (JEFFREY; REYNOLDS, 1999) que comparou as preferências estéticas de uma amostra de arquitetos, planejadores e pessoas leigas. Neste estudo foi observado que os arquitetos possuíam padrões de preferência diferentes e mais homogêneos, enquanto uma considerável convergência de opiniões foi encontrada entre os planejadores e os leigos. Jeffrey e Reynolds (1999) explicam as diferenças com base na existência de um código de elite ou profissional compartilhado pelos arquitetos em oposição a um código popular compartilhado pela maioria dos planejadores e pessoas leigas. Contudo, eles salientam que as preferências estéticas desses três grupos tendiam a apresentar uma concordância considerável com relação às edificações que eram intensamente apreciadas ou depreciadas. Por outro lado, estudos têm demonstrado que arquitetos e pessoas leigas com formação diferem em suas preferências por estilos de edificações e nos significados inferidos a partir de tais estilos (DEVLIN; NASAR, 1989; FAWCETT; ELLINGHAM; PLATT, 2008; UZZEL; JONES, 2000). Arquitetos avaliaram uma arquitetura residencial mais incomum e diferenciada como mais significativa, clara, coerente, agradável e relaxante, enquanto não arquitetos julgaram de maneira similar uma arquitetura residencial mais convencional e popular (DEVLIN; NASAR, 1989; UZZEL; JONES, 2000). Gifford et al. (2000) salientam que não é surpresa o fato de arquitetos perceberem ambientes físicos diferentemente de não arquitetos devido às diferentes histórias de aprendizado dos dois grupos, sendo os distintos efeitos provocados por essas diferenças educacionais também mencionadas por Fawcett, Ellingham e Platt (2008).

Contudo, parece faltar em vários dos estudos mencionados uma maior consideração acerca das possíveis explicações para as avaliações e preferências estéticas com base nas características das edificações. Um melhor conhecimento de tais explicações também possibilita corroborar os pressupostos da estética empírica ou da estética filosófica. Assim, a validação das avaliações estéticas através da identificação de regularidades entre as respostas das pessoas e de explicações baseadas nas características dos elementos avaliados indicaria um suporte para a abordagem adotada pela estética empírica e uma rejeição da abordagem adotada pela estética filosófica. Igualmente, existe a necessidade de um melhor entendimento acerca do impacto gerado pelas características formais de uma composição arquitetônica e pelas associações simbólicas nas avaliações estéticas, e, logo, na qualidade estética de uma composição arquitetônica. Embora diferenças tenham sido encontradas entre 
avaliações estéticas de arquitetos e aqueles sem formação em arquitetura, não existem evidências conclusivas sobre a existência de tais diferenças, além de existir a necessidade da verificação da existência de tais diferenças em ambientes distintos dos anglo-saxões, onde parte expressiva dos estudos envolvendo avaliações estéticas tem sido realizada. Ainda, não existem evidências conclusivas quanto às possíveis diferenças ou similaridades entre arquitetos, não arquitetos com formação universitária e pessoas sem formação universitária no tocante à percepção das ideias de ordem e desordem e dos diferentes níveis de estímulo visual. Portanto, este artigo tem como objetivo a análise da relação entre composição arquitetônica e qualidade estética, considerando os pressupostos da estética filosófica e da estética empírica através do exame das avaliações e das suas razões. É investigado o papel da estética formal e da estética simbólica em explicar tais avaliações, por meio dos conceitos de familiaridade e valor histórico. Como consequência, edificações históricas e contemporâneas com distintos níveis de ordem e estímulo visual são avaliadas por usuários do ambiente urbano da cidade de Porto Alegre, com formação em arquitetura, com formação em outras áreas ou sem formação universitária.

\section{Metodologia}

Questionários e entrevistas estruturadas foram realizados em um tempo médio de 30 minutos, com 60 arquitetos (de regra, professores da Faculdade de Arquitetura da UFRGS), 60 não arquitetos com formação universitária em cursos que não tratam de estética (majoritariamente professores da Escola de Engenharia e das Faculdades de Educação, Economia e Direito da UFRGS) e 60 respondentes com o primeiro ou segundo grau (funcionários das Faculdades de Arquitetura, Educação, Economia e Direito, da Escola de Engenharia e da Reitoria da UFRGS). Esses 180 respondentes eram familiarizados com Porto Alegre, residindo ou trabalhando na cidade há pelo menos um ano, e foram contatados pessoalmente, através de mensagens por e-mail e telefonemas.

A razão para a aplicação dos questionários está na comparação das respostas dadas ao conjunto de perguntas feitas aos respondentes de maneira que pudessem ser analisadas estatisticamente (REIS; LAY, 1995). As perguntas eram fechadas, de escolha simples e de escolha múltipla, conforme segue: "Avalie a aparência do edifício 1 ao 6:" [muito bonito; bonito; nem bonito nem feio; feio; muito feio]; "Classifique o edifício 1 ao 6 como:" [conhecido ou familiar; desconhecido ou não familiar]; "Ordene os edifícios, do 1 ao 6, do mais para o menos preferido quanto à aparência:"; "Indique as principais razões que justifiquem o edifício mais preferido: ( ) similaridade entre as formas; ( ) falta de similaridade entre as formas; ( ) relação ordenada entre as formas; ( ) relação desordenada entre as formas; ( ) regularidade geométrica das formas; ( ) falta de regularidade geométrica das formas; ( ) existência de estímulo visual; ( ) falta de estímulo visual; ( ) outro "; "Indique as principais razões que justifiquem o edifício menos preferido:" [mesmas da questão anterior].

A aplicação das entrevistas, por sua vez, está baseada no aprofundamento do conhecimento, possibilitando explicações que não são possíveis de ser detectadas dentro do escopo de questionários (REIS; LAY, 1995) sobre o impacto da estética simbólica, especificamente quanto à familiaridade e ao valor histórico das edificações. Assim, foram solicitadas explicações aos entrevistados sobre possíveis impactos desses aspectos nas avaliações das edificações, como segue: "Explique se o fato de algum edifício the ser 'conhecido ou familiar' afetou a sua avaliação"; "Explique se o fato de algum edifício ser antigo ou ter valor histórico afetou a sua avaliação". Ainda, foi possível identificar e comparar as explicações dadas pelos arquitetos, não arquitetos com formação universitária e pessoas sem formação universitária. As edificações foram apresentadas pelos pesquisadores durante a aplicação dos questionários através de um kit fotográfico constituído por duas pranchas em formato A3, com as fotografias coloridas de três edificações históricas de Porto Alegre (Figura 1) e três edificações contemporâneas de Porto Alegre (Figura 2), categorizadas conforme segue:

(a) Edifício 1: edifício histórico com desordem (Figura 3);

(b) Edifício 2: edifício histórico com ordem e pouco estímulo (Figura 4);

(c) Edifício 3: edifício histórico com ordem e estímulo (Figura 5);

(d) Edifício 4: edifício contemporâneo com desordem (Figura 6);

(e) Edifício 5: edifício contemporâneo com ordem e estímulo (Figura 7); e

(f) Edifício 6: edifício contemporâneo com ordem e pouco estímulo (Figura 8).

Visando à facilidade de compreensão e comparação entre as edificações pelos respondentes assim como a facilidade de manuseio por eles e pelos pesquisadores, quando dos 
deslocamentos destes para aplicação dos questionários e realização das entrevistas, foram determinados o tamanho da prancha (A3) e a quantidade e as dimensões das edificações em cada prancha. A utilização de fotografia colorida para mostrar as edificações está fundamentada em seu uso recorrente em estudos envolvendo avaliações estéticas e em sua adequação para simular um ambiente real (SANOFF, 1991). Considerando que os ângulos de visão utilizados para as fotografias não têm um efeito significativo sobre as avaliações estéticas, sendo determinantes para estas as características arquitetônicas (STAMPS, 2000), as edificações foram apresentadas somente mediante vistas frontais. As edificações foram fotografadas em dias com níveis de iluminação similares, evitando-se horários com incidência solar nas edificações, devido aos contrastes gerados por áreas iluminadas e áreas sombreadas.

Considerando as categorias apresentadas, edificações com ordem e estímulo visual são caracterizadas por uma clara organização entre os elementos arquitetônicos e pela existência evidente de estímulo visual ou foco de atenção (Figuras 5 e 7). Edificações com ordem e pouco estímulo visual são caracterizadas por uma clara organização entre os elementos arquitetônicos que as compõem, mas com fraco estímulo visual, possibilitando a percepção de monotonia (Figuras 4 e 8 ). Edificações com desordem são caracterizadas pela ausência de uma clara organização entre os elementos arquitetônicos que as compõem, ficando comprometida a percepção de ordem (Figuras 3 e $6)$.
As edificações históricas de Porto Alegre são aquelas consideradas de valor histórico e/ou artístico e tombadas por instituições públicas em nível local (Equipe do Patrimônio Histórico e Cultural - EPAHC), estadual (Instituto do Patrimônio Histórico e Artístico do Estado do Rio Grande do Sul - IPHAE) e federal (Instituto do Patrimônio Histórico e Artístico Nacional IPHAN), responsáveis por preservar o patrimônio cultural. As edificações contemporâneas de Porto Alegre são edificações comerciais construídas a partir de 1990 que não constituem obras arquitetônicas de referência e/ou de divulgação pela mídia, de maneira a eliminar ou minimizar possíveis impactos nas avaliações estéticas dos respondentes gerados pela maior valorização de uma obra em detrimento de outra. Ainda, as edificações selecionadas não deveriam sugerir diferenças de "status social" e de uso. Por exemplo, não foram utilizadas edificações comerciais contemporâneas com telhado aparente com o intuito de dificultar ou impedir eventuais associações com residências nas quais os respondentes gostariam ou não de residir.

As fotografias das edificações foram editadas no programa Corel Photo Paint, visando, além de ajustes estéticos para o adequado enquadramento nas categorias adotadas, à supressão de distorções, pessoas, veículos, sombras, abóbadas celestes e elementos urbanos, tais como vegetação, postes e fios de luz, lixeiras e elementos de comunicação visual urbana, que pudessem interferir na avaliação estética das edificações (por exemplo, Figuras 9, 10,11 e 12 ).

Figura 1 - Prancha 1: edifícios históricos de Porto Alegre

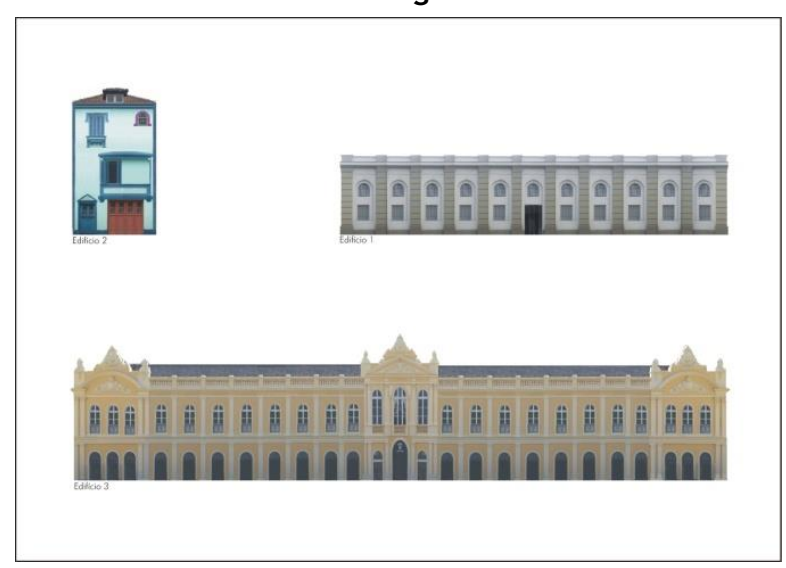

196 Reis, A. T. da L.; Biavatti, C. D.; Pereira, M. L. 
Figura 2 - Prancha 2: edifícios contemporâneos de Porto Alegre

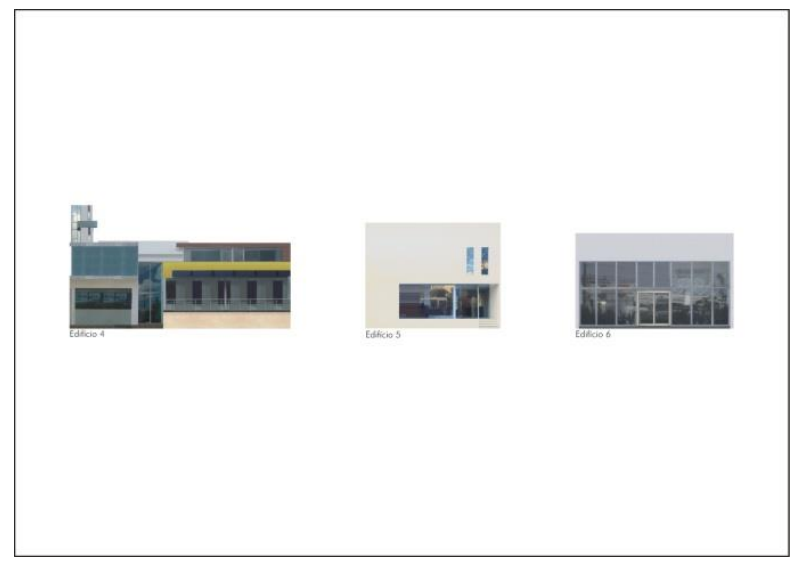

Figura 3 - Edifício 1: edifício histórico com desordem

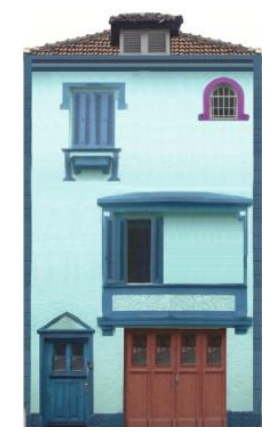

Figura 4 - Edifício 2: edifício histórico com ordem e pouco estímulo

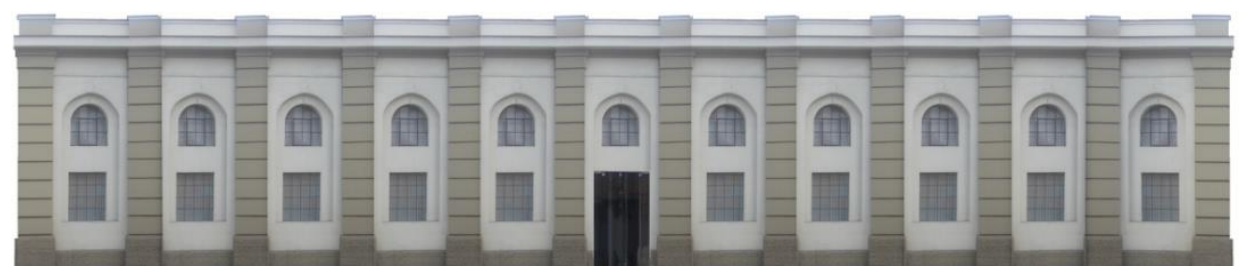

Figura 5 - Edifício 3: edifício histórico com ordem e estímulo

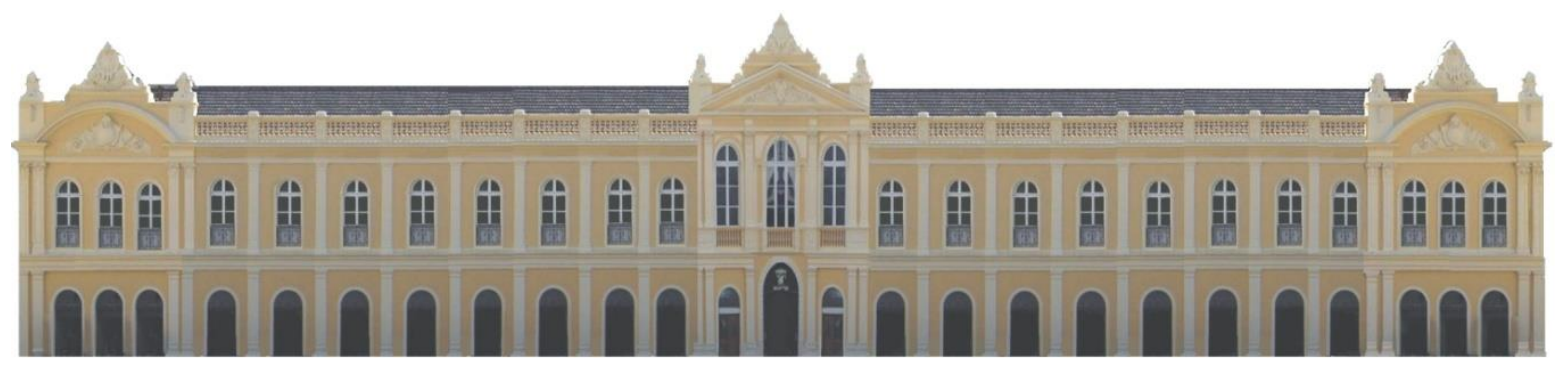


Figura 6 - Edifício 4: edifício contemporâneo com desordem

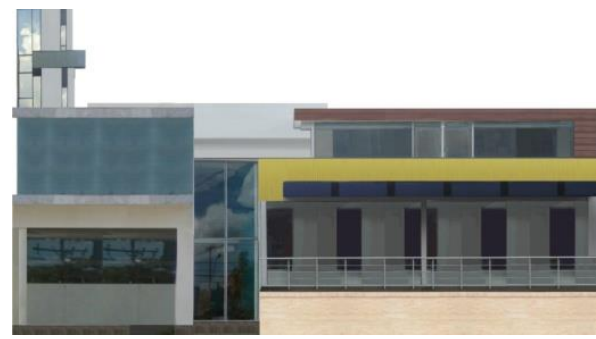

Figura 7 - Edifício 5: edifício contemporâneo com ordem e estímulo

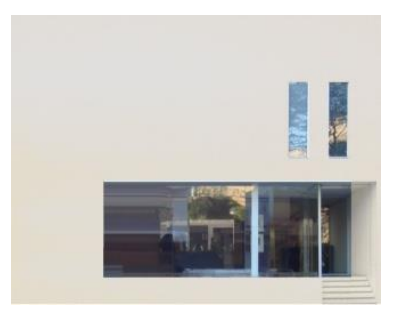

Figura 8 - Edifício 6: edifício contemporâneo com ordem e pouco estímulo

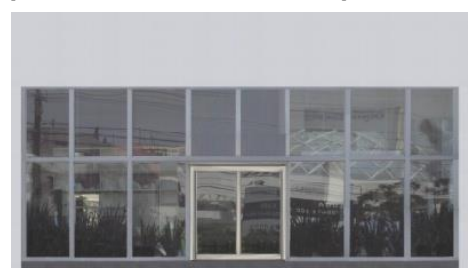

Figura 9 - Conjunto na Rua Fernando Machado, tombado pelo EPAHC

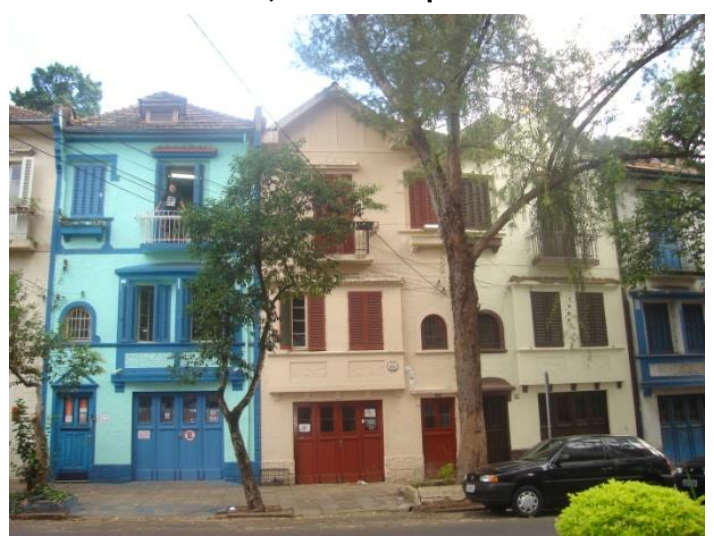

Figura 10 - Edifício histórico com desordem - editado no Corel Photo Paint

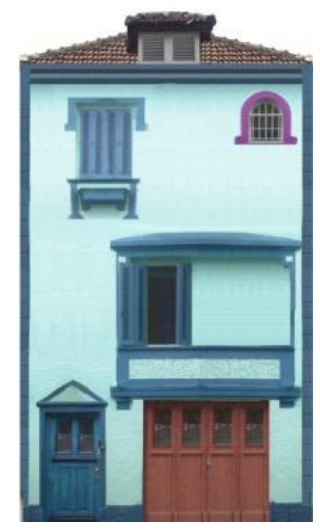

198 Reis, A. T. da L.; Biavatti, C. D.; Pereira, M. L. 
Figura 11 - Loja Bontempo, na Av. Nilo Peçanha - edifício contemporâneo

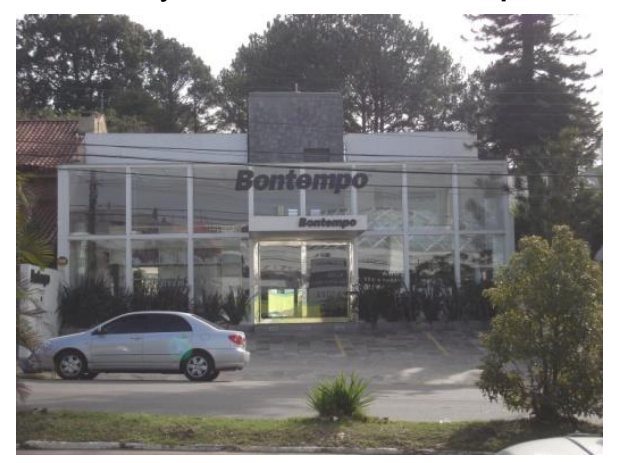

Figura 12 - Loja Bontempo - edifício contemporâneo com ordem e pouco estímulo - editado no Corel Photo Paint

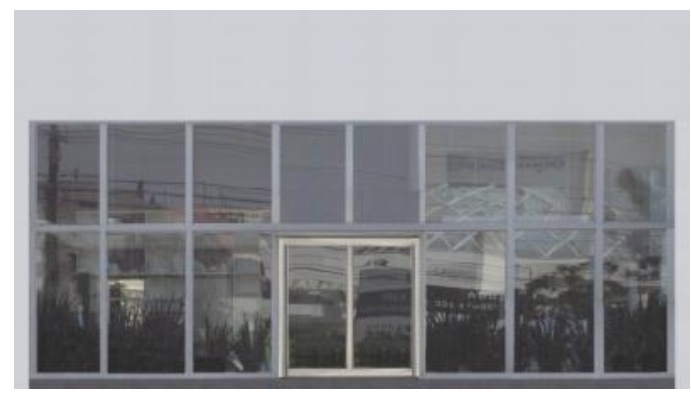

Várias edificações foram editadas, e testes foram realizados (incluindo o estudo piloto) para examinar a adequação das edificações às categorias estabelecidas. Especificamente, o estudo piloto teve como principais objetivos verificar:

(a) a compreensão das questões a serem utilizadas no questionário e na entrevista;

(b) a clareza das imagens e a adequação das edificações para cada uma das três categorias estéticas (ordem e estímulo, ordem e pouco estímulo, e desordem); e

(c) o tempo médio necessário para que pessoas com distintos níveis e tipos de escolaridade respondessem ao questionário e à entrevista.

O estudo piloto foi realizado com 15 participantes, sendo 5 arquitetos, 5 não arquitetos com formação universitária e 5 pessoas sem formação universitária, funcionários e professores da Faculdade de Arquitetura da UFRGS e alguns de familiares dos pesquisadores.

Os dados obtidos por meio dos questionários foram tabulados no programa estatístico PASW Statistics 8 e analisados por meio de testes estatísticos não paramétricos, como KruskalWallis e Kendall W (por exemplo, Lay e Reis, 2005). O primeiro identifica a existência de uma diferença estatisticamente significativa entre as avaliações realizadas por cada um dos três grupos de respondentes para cada uma das seis edificações. O último revela a presença de uma diferença estatisticamente significativa entre as avaliações realizadas para as seis edificações por cada um dos três grupos. Os dados das entrevistas (respostas a questões do tipo "Explique se o fato de algum edifício lhe ser 'conhecido ou familiar' afetou a sua avaliação") foram analisados através das frequências e significados das respostas.

\section{Resultados}

De acordo com os objetivos da pesquisa, os resultados são apresentados a seguir.

\section{Composição arquitetônica e qualidade estética: estética filosófica e estética empírica}

A análise da relação entre composição arquitetônica e qualidade estética, considerando os pressupostos da estética filosófica e da estética empírica, é apresentada através dos resultados obtidos com as avaliações estéticas das seis edificações com distintos níveis de ordem e estímulo visual. Através do teste estatístico Kendall W são identificadas diferenças entre as avaliações das seis edificações pelo total dos 180 respondentes e pelos respondentes de cada grupo. Uma diferença estatisticamente significativa foi 
encontrada entre as avaliações estéticas dos edifícios realizadas pela amostra total de 180 respondentes (Kendall $\mathrm{W}, \quad \chi 2=287,101$, sig. $=0,000$ ), pela amostra de arquitetos (Kendall $\mathrm{W}, \chi 2=119,747$, sig. $=0,000)$, pela amostra de não arquitetos com formação universitária (Kendall W, $\chi 2=121,54, \quad$ sig. $=0,000)$ e pela amostra de respondentes sem formação universitária (Kendall $\mathrm{W}, \chi 2=90,15$, sig. $=0,000)$. Logo, composições arquitetônicas caracterizadas por distintos níveis de ordem e estímulo visual foram avaliadas diferentemente, indicando qualidades estéticas heterogêneas.

As edificações mais bem avaliadas pelo total da amostra de 180 respondentes foram a 3 e a 2 (com, respectivamente, $92,7 \%$ e $57,3 \%$ de avaliações positivas). Embora neste último caso a avaliação positiva não tenha sido expressiva, a avaliação negativa foi pequena $(8,9 \%)$ (Tabela 1$)$. As edificações mais mal avaliadas pelo total da amostra foram a $4(41,1 \%)$, a $1(31,7 \%)$, a 6 $(24,4 \%)$ e a $5(22,2 \%)$. Embora no caso das edificações 5,1 e 6 as avaliações positivas $(49,4 \%$, $38,3 \%$ e $30,5 \%$ respectivamente) tenham sido predominantes, as avaliações negativas foram expressivas (Tabela 1). As edificações mais bem avaliadas pelos arquitetos foram a $3(91,7 \%)$, a 5 $(78,3 \%)$ e a $2(55 \%)$ (Tabela 1$)$. As edificações mais mal avaliadas pelos arquitetos foram a 1 $(45 \%)$, a $4(38,3 \%)$ e a $6(20 \%)$. Embora no caso do edifício 6 a avaliação positiva $(28,3 \%)$ tenha sido predominante, a avaliação negativa foi expressiva (Tabela 1). As edificações mais bem avaliadas pelos não arquitetos com formação universitária foram a $3(98,4 \%)$ e a $2(63,4 \%)$ (Tabela 1). As edificações mais mal avaliadas pelos não arquitetos foram a $4(56,6 \%)$, a $6(35 \%)$, a $5(33,4 \%)$ e a $1(28,3 \%)$. Embora no caso das edificações 1 e 5 as avaliações positivas tenham sido predominantes $(41,6 \%$ e $36,6 \%$ respectivamente), as avaliações negativas foram expressivas (Tabela 1). As edificações mais bem avaliadas por aqueles sem formação universitária foram a $3(88,3 \%)$ e a $2(53,3 \%)$ (Tabela 1$)$. As edificações mais mal avaliadas por este grupo foram a $5(31,7 \%)$, a $4(28,3 \%)$, a $1(21,6 \%)$ e a 6 $(18,3 \%)$. Embora nestes casos as avaliações positivas tenham sido preponderantes (Edifício 1 45\%; Edifício 4 - 41,7\%; Edifício 5 - 33,3\%; e Edifício $6-33,3 \%$ ), as avaliações negativas foram expressivas (Tabela 1).

Assim, o edifício 3 (Figura 5 - edifício histórico com ordem e estímulo) foi mais bem avaliado tanto pelo total da amostra quanto por cada um dos três grupos de respondentes (Tabela 1; Quadro 1), evidenciando o impacto positivo da presença de ordem e estímulo visual nas avaliações estéticas dos respondentes e, logo, numa composição arquitetônica com qualidade estética. Este foi o único edifício, entre os seis, avaliado positivamente (muito bonito ou bonito) por mais de $70 \%$ do total dos respondentes e por $70 \%$ dos 60 respondentes em cada um dos três grupos, percentual este que poderia ser considerado como uma clara indicação de uma composição arquitetônica esteticamente satisfatória. Ainda, o edifício 3, juntamente com o edifício 2 (Figura 4 edifício com ordem e pouco estímulo histórico), e o edifício 5 (Figura 7 - edifício contemporâneo com ordem e estímulo) foram os únicos a ter uma avaliação positiva superior à avaliação negativa por cada um dos três grupos de respondentes. $\mathrm{O}$ edifício 5 foi também o segundo mais bem avaliado pela clara maioria dos arquitetos (Tabela 1; Quadro 1).

Por outro lado, o edifício 4 (Figura 6 - edifício com desordem contemporâneo) foi o mais mal avaliado pelo total da amostra (o único com avaliação negativa superior à positiva), assim como pelos não arquitetos com formação superior, e o mais mal avaliado pelos arquitetos depois do edifício 1 (edifício histórico com desordem). O edifício 4 também foi o único a ter uma avaliação estética negativa por parte de, no mínimo, $25 \%$ dos respondentes em cada um dos três grupos e do total dos 180 respondentes, percentual este que não pode ser desprezado (Tabela 1; Quadro 1). Logo, fica evidenciado o impacto estético negativo gerado pela "desordem". Embora para os respondentes sem formação universitária nenhum edifício tenha tido avaliação positiva inferior à avaliação negativa, o edifício 5 (Figura 7 - edifício contemporâneo com ordem e estímulo) foi o mais mal avaliado, seguido pelos edifícios 4 e 1 . Além da avaliação altamente negativa pelos arquitetos, o edifício 1 foi o segundo mais mal avaliado pelo total da amostra. Os edifícios 4 e 1 foram os únicos a terem uma avaliação negativa maior do que a avaliação positiva pelos arquitetos, enquanto o mesmo ocorreu na avaliação dos edifício 4 e 6 pelos não arquitetos com formação universitária. Considerando também que o edifício 6 foi julgado como nem bonito nem feio por $45 \%$ da amostra total de respondentes, pode-se inferir que, embora exista organização na composição do edifício, o pouco estímulo não foi suficiente para gerar reações estéticas mais positivas (Tabela 1; Quadro $1)$. 
Tabela 1 - Graus de satisfação com a aparência dos edifícios

\begin{tabular}{|c|c|c|c|c|c|c|}
\hline $\begin{array}{l}\text { Níveis de } \\
\text { satisfação }\end{array}$ & $\begin{array}{c}\text { Edifício 1 } \\
\text { Fig.3 } \\
\end{array}$ & $\begin{array}{c}\text { Edifício } 2 \\
\text { Fig.4 } \\
\end{array}$ & $\begin{array}{c}\text { Edifício } 3 \\
\text { Fig.5 } \\
\end{array}$ & $\begin{array}{c}\text { Edifício } 4 \\
\text { Fig.6 } \\
\end{array}$ & $\begin{array}{c}\text { Edifício } 5 \\
\text { Fig.7 } \\
\end{array}$ & $\begin{array}{c}\text { Edifício } 6 \\
\text { Fig.8 } \\
\end{array}$ \\
\hline \multicolumn{7}{|c|}{ Total da amostra -180 respondentes } \\
\hline Muito bonito & $12,2 \%$ & $11,7 \%$ & $59,4 \%$ & $3,9 \%$ & $15,0 \%$ & $7,2 \%$ \\
\hline Bonito & $26,1 \%$ & $45,6 \%$ & $33,3 \%$ & $26,1 \%$ & $34,4 \%$ & $23,3 \%$ \\
\hline $\begin{array}{l}\text { Nem bonito nem } \\
\text { feio }\end{array}$ & $30,0 \%$ & $33,9 \%$ & $6,1 \%$ & $28,9 \%$ & $28,3 \%$ & $45,0 \%$ \\
\hline Feio & $21,1 \%$ & $8,3 \%$ & $0,6 \%$ & $32,2 \%$ & $19,4 \%$ & $18,3 \%$ \\
\hline Muito feio & $10,6 \%$ & $0,6 \%$ & $0,6 \%$ & $8,9 \%$ & $2,8 \%$ & $6,1 \%$ \\
\hline mvo Kendall & 3,02 & 3,79 & 5,28 & 2,58 & 3,40 & 2,94 \\
\hline \multicolumn{7}{|c|}{ Arquitetos -60 respondentes } \\
\hline Muito bonito & $8,3 \%$ & $13,3 \%$ & $56,7 \%$ & $8,3 \%$ & $28,3 \%$ & $8,3 \%$ \\
\hline Bonito & $20,0 \%$ & $41,7 \%$ & $35,0 \%$ & $20,0 \%$ & $50,0 \%$ & $20,0 \%$ \\
\hline $\begin{array}{l}\text { Nem bonito nem } \\
\text { feio }\end{array}$ & $26,7 \%$ & $35,0 \%$ & $6,7 \%$ & $33,3 \%$ & $20,0 \%$ & $51,7 \%$ \\
\hline Feio & $25,0 \%$ & $10,0 \%$ & $1,7 \%$ & $25,0 \%$ & $1,7 \%$ & $11,7 \%$ \\
\hline Muito feio & $20,0 \%$ & $0,0 \%$ & $0,0 \%$ & $13,3 \%$ & $0,0 \%$ & $8,3 \%$ \\
\hline mvo Kendall & 2,47 & 3,66 & 5,13 & 2,55 & 4,36 & 2,83 \\
\hline mvo K-W & 75,28 & 89,39 & 87,76 & 90,76 & 122,15 & 91,48 \\
\hline \multicolumn{7}{|c|}{ Não arquitetos com formação universitária - 60 respondentes } \\
\hline Muito bonito & $18,3 \%$ & $11,7 \%$ & $66,7 \%$ & $1,7 \%$ & $8,3 \%$ & $5,0 \%$ \\
\hline Bonito & $23,3 \%$ & $51,7 \%$ & $31,7 \%$ & $18,3 \%$ & $28,3 \%$ & $25,0 \%$ \\
\hline $\begin{array}{l}\text { Nem bonito nem } \\
\text { feio }\end{array}$ & $30,0 \%$ & $30,0 \%$ & $0,0 \%$ & $23,3 \%$ & $30,0 \%$ & $35,0 \%$ \\
\hline Feio & $20,0 \%$ & $6,7 \%$ & $0,0 \%$ & $48,3 \%$ & $26,7 \%$ & $30,0 \%$ \\
\hline Muito feio & $8,3 \%$ & $0,0 \%$ & $1,7 \%$ & $8,3 \%$ & $6,7 \%$ & $5,0 \%$ \\
\hline mvo Kendall & 3,35 & 4,03 & 5,43 & 2,32 & 3,03 & 2,84 \\
\hline mvo K-W & 96,46 & 95,76 & 98,46 & 76,60 & 74,76 & 83,78 \\
\hline \multicolumn{7}{|c|}{ Respondentes sem formação universitária - 60 respondentes } \\
\hline Muito bonito & $10,0 \%$ & $10,0 \%$ & $55,0 \%$ & $1,7 \%$ & $8,3 \%$ & $8,3 \%$ \\
\hline Bonito & $35,0 \%$ & $43,3 \%$ & $33,3 \%$ & $40,0 \%$ & $25,0 \%$ & $25,0 \%$ \\
\hline $\begin{array}{l}\text { Nem bonito nem } \\
\text { feio }\end{array}$ & $33,3 \%$ & $36,7 \%$ & $11,7 \%$ & $30,0 \%$ & $35,0 \%$ & $48,3 \%$ \\
\hline Feio & $18,3 \%$ & $8,3 \%$ & $0,0 \%$ & $23,3 \%$ & $30,0 \%$ & $13,3 \%$ \\
\hline Muito feio & $3,3 \%$ & $1,7 \%$ & $0,0 \%$ & $5,0 \%$ & $1,7 \%$ & $5,0 \%$ \\
\hline mvo Kendall & 3,23 & 3,68 & 5,26 & 2,88 & 2,82 & 3,14 \\
\hline mvo K-W & 99,76 & 86,35 & 85,28 & 104,14 & 74,59 & 96,24 \\
\hline
\end{tabular}

Nota: mvo Kendall = média dos valores ordinais obtida por meio do teste Kendall W; mvo K-W = média dos valores ordinais obtida por meio do teste Kruskal-Wallis; a comparação entre os valores de mvo Kendall deve ser feita na horizontal, entre os edifícios; a comparação entre os valores mvo K-W deve ser feita na vertical, entre os grupos. 
Quadro 1 - Edifícios mais satisfatórios e insatisfatórios esteticamente

\begin{tabular}{|c|c|c|c|}
\hline Amostra Total 180 & Arquitetos (60) & $\begin{array}{c}\text { Não arquitetos com } \\
\text { formação universitária } \\
(60)\end{array}$ & $\begin{array}{c}\text { Respondentes sem } \\
\text { formação superior } \\
(60)\end{array}$ \\
\hline \multicolumn{4}{|c|}{ Edifícios mais satisfatórios } \\
\hline $\begin{array}{l}\text { Edifício } 3 \text { (Fig. } 5 \text { - } \\
\text { edifício histórico com } \\
\text { ordem e estímulo) }\end{array}$ & $\begin{array}{l}\text { Edifício } 3 \text { (Fig. } 5 \text { - } \\
\text { edifício histórico com } \\
\text { ordem e estímulo) } \\
\text { Edifício } 5 \text { (Fig. } 7 \text { - } \\
\text { edifício contemporâneo } \\
\text { com ordem e estímulo) }\end{array}$ & $\begin{array}{l}\text { Edifício } 3 \text { (Fig. } 5 \text { - } \\
\text { edifício histórico com } \\
\text { ordem e estímulo) }\end{array}$ & $\begin{array}{l}\text { Edifício } 3 \text { (Fig. } 5 \text { - } \\
\text { edifício histórico com } \\
\text { ordem e estímulo) }\end{array}$ \\
\hline \multicolumn{4}{|c|}{ Edifícios mais insatisfatórios } \\
\hline $\begin{array}{l}\text { Edifício } 4 \text { (Fig. } 6- \\
\text { edifício contemporâneo } \\
\text { com desordem) }\end{array}$ & $\begin{array}{l}\text { Edifício } 1 \text { (Fig. } 3- \\
\text { edifício histórico com } \\
\text { desordem) } \\
\text { Edifício } 4 \text { (Fig. } 6 \text { - } \\
\text { edifício contemporâneo } \\
\text { com desordem) }\end{array}$ & $\begin{array}{l}\text { Edifício } 4 \text { (Fig. } 6- \\
\text { edifício contemporâneo } \\
\text { com desordem) }\end{array}$ & $*$ \\
\hline
\end{tabular}

Nota: Os edifícios mais satisfatórios foram organizados a partir do mais satisfatório e possuem a porcentagem de respondentes satisfeitos visivelmente maior que a de insatisfeitos; os edifícios mais insatisfatórios foram organizados a partir do mais insatisfatório e possuem a porcentagem de respondentes insatisfeitos visivelmente maior que a de satisfeitos; ${ }^{*}=$ nenhum edifício possui a porcentagem de indivíduos insatisfeitos visivelmente maior que a de satisfeitos.

A ordem de preferência tende a corroborar os resultados obtidos com a avaliação individual das edificações (Tabela 1; Quadro 1), conforme segue:

(a) o claro impacto estético positivo da ideia de ordem e estímulo, representada pelo edifício 3, tanto para a amostra total quanto para as amostras de arquitetos, não arquitetos com formação universitária e respondentes sem formação universitária (Tabela 2);

(b) o impacto negativo da ideia de desordem, representada pelo edifício 4 , o menos preferido pelo total da amostra, pelos não arquitetos com formação universitária e respondentes sem formação universitária, e o menos preferido pelos arquitetos após o edifício 1 , também caracterizado pela ideia de desordem (Tabela 2); e

(c) o impacto positivo da ideia de ordem com pouco estímulo, representada pelo edifício 2 , o segundo na ordem de preferência, e o impacto bem menos positivo desta ideia representada pelo edifício 6 , o penúltimo na ordem de preferência, para o total da amostra (Tabela 2).

A ordem de preferência dos edifícios para os arquitetos revela claramente a preferência pelos edifícios com ordem e estímulo (3 e 5) e a não preferência pelos edifícios com desordem (1 e 4), o que confirma suas avaliações individuais das cenas (Tabelas 1 e 2). A ordem de preferência dos edifícios para os não arquitetos com formação universitária corrobora suas avaliações individuais das edificações e mostra a preferência por um edifício com ordem e estímulo (3) e a menor preferência por um edifício com desordem (4), embora um edifício com desordem (1) tenha sido preferido a um edifício com ordem e estímulo (5) e a um edifício com ordem e pouco estímulo (6) (Tabelas 1 e 2). A ordem de preferência dos edifícios para os respondentes sem formação universitária coincide com a dos não arquitetos com formação universitária, e tende a sustentar suas avaliações individuais dos edifícios, excetuando-se a ordem de preferência dos edifícios 5, 6 e 4, cujas avaliações individuais são mais positivas para o edifício 6 e menos positivas para $o$ edifício 5, com o edifício 4 (o menos preferido) tendo uma avaliação intermediária entre as dos edifícios 6 e 5 (Tabelas 1 e 2).

Conforme os resultados acima, a ordem de preferência das edificações tende a ser sustentada pelas avaliações individuais dos edifícios, existindo uma clara tendência para os edifícios com ordem e estímulo a provocarem as reações estéticas mais positivas, e para os edifícios com desordem a provocarem as reações estéticas menos positivas. Por sua vez, os edifícios com ordem e pouco estímulo provocaram reações estéticas mais variadas (Tabelas 1 e 2).

As razões mencionadas pelos respondentes para justificar suas preferências evidenciam a importância do estímulo visual e da relação ordenada para percepções estéticas mais positivas e o impacto da falta de estímulo visual e da relação desordenada para percepções estéticas menos positivas (Tabela 3). Contudo, observa-se que os arquitetos privilegiam a relação ordenada e a regularidade geométrica, enquanto os não 
arquitetos com formação universitária e aqueles sem formação universitária privilegiam a existência de estímulo visual, para justificar o edifício mais preferido. Por outro lado, para justificar o edifício menos preferido, salienta-se a indicação da existência de relação desordenada pelos arquitetos, enquanto para os não arquitetos com formação universitária e para aqueles sem formação universitária a principal razão é a falta de estímulo visual (Tabela 3 ).

\section{Composição arquitetônica e qualidade estética: estética formal e estética simbólica}

A análise da relação entre composição arquitetônica e qualidade estética, considerando o papel da estética formal e da estética simbólica em explicar tal relação, é apresentada através dos resultados obtidos por meio do exame das relações entre as avaliações das seis edificações e seus níveis de familiaridade e valor histórico, pelo total dos 180 respondentes e pelos respondentes de cada grupo, e da identificação de diferenças entre tais avaliações através do teste estatístico Kendall W. Considerando a relação entre a percepção predominante de familiaridade ou não familiaridade e a ordem de preferência de cada um dos seis edifícios, observa-se para o total dos 180 respondentes que, entre os três edifícios mais preferidos (3, 2 e 5), apenas para o edifício 5 a percepção de familiaridade não foi predominante (Tabela 4). O edifício 3, o mais preferido, foi classificado como conhecido ou familiar pela quase totalidade dos respondentes $(97,7 \%)$. Entre os três edifícios menos preferidos (4, 6 e 1$)$ predomina a percepção de não familiaridade. $\mathrm{O}$ edifício menos preferido (4) foi classificado como desconhecido ou não familiar pela expressiva maioria dos respondentes $(80,0 \%)$ (Tabela 4). Considerando-se a relação entre a maior ou menor preferência e a percepção predominante de familiaridade ou não familiaridade, observa-se, mesmo para aqueles edifícios onde não foi encontrada uma relação estatisticamente significativa (teste Mann-Whitney) entre as variáveis preferência e familiaridade, que houve maior preferência pelo edifício por parte dos respondentes que o perceberam como familiar (Tabela 4).

Considerando apenas os 60 respondentes arquitetos, entre os três edifícios mais preferidos $(3,5$ e 2$)$, apenas para o edifício 5 a percepção de familiaridade não foi predominante, sendo idêntica à percepção de não familiaridade (Tabela 4). O edifício 3, o mais preferido, foi classificado como conhecido ou familiar pela totalidade dos arquitetos. Entre os três edifícios menos preferidos (4, 6 e 1) predomina a percepção de não familiaridade, excetuando o edifício 6 . O edifício menos preferido (1) foi classificado como desconhecido ou não familiar pela expressiva maioria dos arquitetos $(80,0 \%)$ (Tabela 4). Observa-se também para os seis edifícios, mesmo para aqueles em que não foi encontrada uma relação estatisticamente significativa (teste MannWhitney) entre as variáveis preferência e familiaridade, que houve maior preferência pelo edifício por parte dos arquitetos que o perceberam como familiar (Tabela 4).

Tabela 2 - Ordem de preferência dos edifícios quanto à aparência

\begin{tabular}{c|c|c|c|c|c|c|c|c|c|c}
\hline \multicolumn{2}{c|}{ Total } & \multicolumn{3}{c|}{ Arquitetos } & \multicolumn{3}{c|}{$\begin{array}{c}\text { Não arquitetos com } \\
\text { formação superior }\end{array}$} & \multicolumn{3}{c}{$\begin{array}{c}\text { Respondentes sem formação } \\
\text { superior }\end{array}$} \\
\hline Edifício & mv K & Edifício & mv K & mv K-W & Edifício & mv K & mv K-W & Edifício & mv K & mv K-W \\
\hline $3(983)$ & 5,46 & $3(313)$ & 5,22 & 77,43 & $3(340)$ & 5,67 & 100,95 & $3(330)$ & 5,50 & 93,13 \\
$2(690)$ & 3,83 & $5(265)$ & 4,42 & 122,72 & $2(245)$ & 4,08 & 97,95 & $2(229)$ & 3,82 & 92,38 \\
$5(629)$ & 3,49 & $2(216)$ & 3,60 & 81,18 & $1(202)$ & 3,37 & 102,65 & $1(187)$ & 3,12 & 94,38 \\
$1(534)$ & 2,97 & $6(172)$ & 2,87 & 92,96 & $5(191)$ & 3,18 & 78,96 & $5(173)$ & 2,88 & 69,83 \\
$6(498)$ & 2,77 & $4(149)$ & 2,48 & 90,15 & $6(155)$ & 2,58 & 85,33 & $6(171)$ & 2,85 & 93,22 \\
$4(446)$ & 2,48 & $1(145)$ & 2,42 & 74,47 & $4(127)$ & 2,12 & 76,38 & $4(170)$ & 2,83 & 104,97 \\
\hline
\end{tabular}

Nota: $\mathrm{mv} \mathrm{K}$ - média dos valores ordinais obtida através do teste Kendall W; mv K-W - média dos valores ordinais obtida através do teste Kruskal-Wallis; coluna 'Edifício' - valor fora dos parênteses = edifício em avaliação [valor entre parênteses = pontuação total recebida, variando da maior (6 pontos) para a menor (1 ponto) preferência por cada respondente]. 
Tabela 3 - Principais razões que justificam a preferência

\begin{tabular}{l|c|c|c|c|c|c}
\hline \multicolumn{1}{c|}{ Razões } & Arquitetos & $\begin{array}{c}\text { N arq c f } \\
\text { sup }\end{array}$ & Resp s f sup & Total & sig & phi \\
\hline \multicolumn{7}{c}{ Edifício mais preferido } \\
\hline Existência de estímulo visual & $51,7 \%$ & $65,0 \%$ & $65,0 \%$ & $60,6 \%$ & no sig & 0,129 \\
Relação ordenada & $66,7 \%$ & $51,7 \%$ & $36,7 \%$ & $51,7 \%$ & 0,004 & 0,245 \\
Regularidade geométrica & $58,3 \%$ & $50,0 \%$ & $26,7 \%$ & $45,0 \%$ & 0,001 & 0,269 \\
Similaridade entre forma & $23,3 \%$ & $48,3 \%$ & $43,3 \%$ & $38,3 \%$ & 0,012 & 0,222 \\
\hline \multicolumn{7}{c}{ Edifício menos preferido } \\
\hline Falta de estímulo visual & $45,0 \%$ & $56,7 \%$ & $76,7 \%$ & $59,4 \%$ & 0,002 & 0,266 \\
Relação desordenada & $63,3 \%$ & $43,3 \%$ & $26,7 \%$ & $44,4 \%$ & 0,000 & 0,302 \\
Falta de similaridade & $26,7 \%$ & $26,7 \%$ & $23,3 \%$ & $25,6 \%$ & no sig & 0,036 \\
Falta de regularidade geométrica & $25,0 \%$ & $25,0 \%$ & $18,3 \%$ & $22,8 \%$ & no sig & 0,075 \\
Regularidade geométrica & $8,3 \%$ & $6,7 \%$ & $1,7 \%$ & $5,6 \%$ & no sig & 0,124 \\
Similaridade entre forma & $3,3 \%$ & $6,7 \%$ & $5,0 \%$ & $5,0 \%$ & no sig & 0,062 \\
\hline
\end{tabular}

Nota: $\mathrm{N}$ arq $\mathrm{c} f$ sup= não arquiteto com formação universitária; Resp $\mathrm{s} f$ sup= respondente sem formação universitária; os valores de sig e phi foram obtidos através de tabulação cruzada; no sig = diferença estatisticamente insignificante, ou seja, sig. >0,05.

Tabela 4 - Familiaridade dos edifícios e influência na ordem de preferência

\begin{tabular}{|c|c|c|c|c|c|c|c|c|c|c|c|c|}
\hline \multirow[t]{2}{*}{ Familiaridade } & \multicolumn{2}{|c|}{ Edifício 1} & \multicolumn{2}{|c|}{ Edifício 2} & \multicolumn{2}{|c|}{ Edifício 3} & \multicolumn{2}{|c|}{ Edifício 4} & \multicolumn{2}{|c|}{ Edifício 5} & \multicolumn{2}{|c|}{ Edifício 6} \\
\hline & $\%$ & $\mathrm{mM}-\mathrm{W}$ & $\%$ & $\mathrm{mM}-\mathrm{W}$ & $\%$ & $\mathrm{mM}-\mathrm{W}$ & $\%$ & mM-W & $\%$ & $\mathrm{mM}-\mathrm{W}$ & $\%$ & $\mathrm{mM}-\mathrm{W}$ \\
\hline \multicolumn{13}{|c|}{ Amostra total - 180 respondentes } \\
\hline Conhec/familiar & 24,4 & 97,18 & 66,1 & 100,45 & 97,7 & 90,8 & 20,0 & 100,96 & 32,2 & 109,83 & 49,4 & 108,99 \\
\hline Desc/n f & 75,6 & 88,34 & 33,9 & 71,08 & 2,3 & 77,5 & 80,0 & 87,89 & 67,8 & 81,31 & 50,6 & 72,42 \\
\hline Sig & \multicolumn{2}{|c|}{ no sig } & \multicolumn{2}{|c|}{0,000} & \multicolumn{2}{|c|}{ no sig } & \multicolumn{2}{|c|}{ no sig } & \multicolumn{2}{|c|}{0,000} & \multicolumn{2}{|c|}{0,000} \\
\hline Posição & \multicolumn{2}{|c|}{$4^{\circ}$} & \multicolumn{2}{|c|}{$2^{\circ}$} & \multicolumn{2}{|c|}{$1^{\circ}$} & \multicolumn{2}{|c|}{$6^{\circ}$} & \multicolumn{2}{|c|}{$3^{\circ}$} & \multicolumn{2}{|c|}{$5^{\circ}$} \\
\hline \multicolumn{13}{|c|}{ Arquitetos -60 respondentes } \\
\hline Conhec/familiar & 20,0 & 33,71 & 76,7 & 32,02 & 100 & 30,50 & 26,1 & 39,54 & 50,0 & 30,80 & 63,3 & 35,62 \\
\hline Desc/n f & 80,0 & 29,70 & 23,3 & 25,50 & 0 & 0 & 73,9 & 28,00 & 50,0 & 30,20 & 36,7 & 21,66 \\
\hline Sig & \multicolumn{2}{|c|}{ no sig } & \multicolumn{2}{|c|}{ no sig } & \multicolumn{2}{|c|}{ no sig } & \multicolumn{2}{|c|}{0,030} & \multicolumn{2}{|c|}{ no sig } & \multicolumn{2}{|c|}{0,002} \\
\hline Posiçãon & \multicolumn{2}{|c|}{$6^{\circ}$} & \multicolumn{2}{|c|}{$3^{\circ}$} & \multicolumn{2}{|c|}{$1^{\circ}$} & \multicolumn{2}{|c|}{$5^{\circ}$} & \multicolumn{2}{|c|}{$2^{\circ}$} & & $4^{\circ}$ \\
\hline & & ão ar & etos & for & cão & niver & ia - & res & dent & & & \\
\hline Conhec & 25,0 & 35,40 & 75,0 & 34,76 & 95,0 & 30,72 & 25,0 & 30,03 & 23,3 & 36,89 & 46,7 & 38,68 \\
\hline Desc/n & 75,0 & 28,87 & 25,0 & 17,73 & 5,0 & 26,33 & 75,0 & 30,66 & 76,7 & 28,55 & 53,3 & 23,34 \\
\hline Sig & & $\operatorname{sig}$ & & 00 & & sig & & $\operatorname{sig}$ & & sig & & 000 \\
\hline Posição na o.p. & & $\circ$ & & $0^{\circ}$ & & $1{ }^{\circ}$ & & 0 & & $5^{\circ}$ & & $4^{\circ}$ \\
\hline & & espol & entes & em for & ação & nivers & ia - & 0 respc & dent & & & \\
\hline Conhec & 28,3 & 29,68 & 46,7 & & 98,3 & 30,81 & 13,3 & 37,19 & 23,3 & 39,86 & 38,3 & 35,93 \\
\hline Desc/n familiar & 71,7 & 30,83 & 53,3 & 25,48 & 1,7 & 12,0 & 86,7 & 29,47 & 76,7 & 27,65 & 61,7 & 27,12 \\
\hline Sig & & sig & & 10 & & sig & & sig & & 019 & & sig \\
\hline Posição na o.p. & & $\circ$ & & $0^{\circ}$ & & $1^{\circ}$ & & $0^{\circ}$ & & $5^{\circ}$ & & $4^{\circ}$ \\
\hline
\end{tabular}

Nota: \% = percentual, obtido para as amostras totais e individuais, que julgou o edifício familiar ou não familiar; $\mathrm{mM}-\mathrm{W}=$ média dos valores ordinais obtida a partir do teste Mann-Whitney entre as variáveis preferência e familiaridade (maior valor= maior preferência); conhec/familiar= edifício conhecido ou familiar; desc/n familiar= edifício desconhecido ou não familiar; posição na o.p= posição do edifício na ordem de preferência (Tabela 2); no sig= diferença estatisticamente insignificante, ou seja, sig. $>0,05$.

Considerando apenas os 60 respondentes não arquitetos com formação universitária, entre os três edifícios mais preferidos (3,2 e 1) a percepção de familiaridade foi predominante, excetuando o edifício 1. O edifício 3 , o mais preferido, foi classificado como conhecido ou familiar pela quase totalidade $(95 \%)$ dos não arquitetos com formação universitária. Entre os três edifícios menos preferidos $(4,5$ e 6$)$ predomina a percepção de não familiaridade, com $75 \%$ percebendo o edifício 4, o menos preferido, como não familiar (Tabela 4). Observa-se também, mesmo para aqueles edifícios em que não foi encontrada uma relação estatisticamente significativa entre as variáveis preferência e familiaridade (com exceção do edifício 4), que houve maior preferência pelo edifício por parte dos não arquitetos com formação universitária que o perceberam como familiar (Tabela 4). Considerando apenas os 60 respondentes sem formação universitária, entre os 
três edifícios mais preferidos $(3,2$ e 1$)$ a percepção de familiaridade foi predominante $(98,3 \%)$ apenas para o edifício 3, o mais preferido. Entre os três edifícios menos preferidos $(4,5$ e 6$)$ predomina a percepção de não familiaridade, principalmente para o edifício $4(86,7 \%)$, o menos preferido pelos respondentes sem formação universitária (Tabela 4). Verifica-se também para os seis edifícios, mesmo para aqueles em que não foi encontrada uma relação estatisticamente significativa entre as variáveis preferência e familiaridade (com exceção do edifício 1), que houve maior preferência pelo edifício por parte dos respondentes sem formação universitária que o perceberam como familiar (Tabela 4).

Assim, esses resultados indicam uma clara relação entre a maior preferência por um edifício e a percepção predominante de familiaridade. Embora tanto para a amostra total quanto para cada um dos três grupos não tenha sido encontrada para alguns edifícios uma relação estatisticamente significativa entre as variáveis preferência e familiaridade, quando tal relação significativa foi encontrada houve maior preferência por aqueles que perceberam o edifício como familiar. Nesse sentido, o edifício 3, o mais preferido pelos respondentes das três categorias, foi também considerado pela notória maioria das três amostras como conhecido ou familiar, destacando-se como o mais conhecido entre os seis analisados. Ainda, o edifício 4, o menos preferido pelos respondentes de duas categorias e pelo total da amostra, foi julgado desconhecido pela maioria da amostra total e das amostras individuais (Tabela 4).

Considerando as informações obtidas através das entrevistas (Tabela 5), realizadas com a intenção de investigar a possível interferência de aspectos simbólicos nas reações estéticas dos respondentes, observa-se um equilíbrio entre as respostas dos 180 entrevistados quanto a terem sido ou não afetados em suas avaliações estéticas pela possível familiaridade das edificações (Tabela 5). Por outro lado, enquanto tal equilíbrio também existe nas respostas dos arquitetos, há opiniões divergentes entre os não arquitetos com formação universitária e aqueles sem formação universitária (Tabela 5). Aqueles arquitetos e não arquitetos com formação universitária que se disseram afetados pela familiaridade apontaram o reconhecimento do Mercado Público de Porto Alegre e o afeto pelo edifício ou pelo que ele representa (Tabela 6) como os principais fatores que atuaram para a predileção do edifício em detrimento das outras cinco edificações analisadas. Essa justificativa foi utilizada também pela minoria dos respondentes sem formação universitária que se consideraram afetados pela familiaridade. Para a maioria destes, o fato de a edificação ser percebida como familiar não afetou a avaliação estética, com um desses entrevistados revelando a importância da estética formal ao informar que "as formas apresentadas e as cores dos edifícios foram levadas em consideração". Ainda, para o número expressivo de arquitetos e não arquitetos com formação universitária que consideraram a familiaridade irrelevante, os atributos formais do edifício foram determinantes para sua apreciação ou rejeição, não importando o nível de familiaridade do edifício.

Embora a maioria da amostra total, dos não arquitetos com formação universitária e dos respondentes sem formação universitária disse ter sido influenciada pelo valor histórico percebido na edificação (Tabela 5), a maioria daqueles que se disseram afetados pelo valor histórico justificou essa influência em função dos aspectos compositivos da edificação (Tabela 6). Logo, os aspectos compositivos, formais e não simbólicos afetaram suas avaliações estéticas. Um dos formados em área distinta da arquitetura disse preferir edificações antigas, pois observa nelas maior cuidado na decoração, e acredita que essas possuam maior valor arquitetônico. Nesse sentido, a clara maioria dos arquitetos não julgou o valor histórico relevante para a predileção ou rejeição do edifício (Tabela 5), com um arquiteto afirmando ter considerado "as características formais, como harmonia, ritmo, cores e alturas" em suas avaliações estéticas. Ainda, os arquitetos (aqueles com maior probabilidade de conhecerem a história das edificações e, consequentemente, o valor histórico delas) perceberam os edifícios 3 (edifício histórico com ordem e estímulo) e 5 (edifício contemporâneo com ordem e estímulo) como os mais satisfatórios, e os edifícios 1 (edifício histórico com desordem) e 4 (edifício contemporâneo com desordem) como os mais insatisfatórios esteticamente, corroborando a importância e primazia dos aspectos formais sobre os simbólicos (Tabelas 1 e 2, Quadro 1). Logo, o valor histórico das edificações não parece ter afetado as avaliações estéticas dos arquitetos. 
Tabela 5 - Entrevistados afetados e não afetados pela familiaridade e valor históricos

\begin{tabular}{l|c|c|c|c|c|c|c|c}
\hline & \multicolumn{2}{|c|}{ Arquitetos } & \multicolumn{2}{c|}{ N arq c sup } & \multicolumn{2}{c|}{ Resp s sup } & \multicolumn{2}{c}{ Total } \\
\cline { 2 - 9 } & Afetados & N afet & Afetados & N afet & Afetados & N afet & Afetados & N afet \\
\hline Quanto à familiaridade & 31 & 29 & 34 & 26 & 24 & 36 & 89 & 91 \\
Quanto ao valor histórico & 19 & 41 & 50 & 10 & 34 & 26 & 103 & 77 \\
\hline
\end{tabular}

Nota: Tabela efetuada com base nas respostas das entrevistas; $\mathrm{N}$ arq $\mathrm{c} f$ sup = não arquitetos com formação superior; Resp $\mathrm{s} f$ sup = respondentes sem formação superior; $\mathrm{N}$ afet. = não afetados por familiaridade e/ou valor histórico.

Tabela 6 - Justificativas relacionadas à familiaridade e ao valor histórico

\begin{tabular}{|c|c|c|c|c|}
\hline \multirow{2}{*}{$\begin{array}{l}\text { Justificativas dos entrevistados afetados pela familiaridade } \\
\text { e pelo valor histórico }\end{array}$} & Arquitetos & $\mathrm{N}$ arq c f sup & Resp s f sup & Total \\
\hline & n.a $(\%)$ & n.a $(\%)$ & n.a $(\%)$ & n.a $(\%)$ \\
\hline \multicolumn{5}{|c|}{ Justificativas relacionadas à familiaridade } \\
\hline Justificativas daqueles afetados pela familiaridade & 31(100) & 34(100) & 24(100) & 89(100) \\
\hline Reconhecimento do Mercado Público & $4(12,90)$ & $9(26,47)$ & $12(50,0)$ & $25(28,08)$ \\
\hline O respondente atribui a lembranças a predileção pelo edifício & $2(6,45)$ & $6(17,64)$ & $1(4,76)$ & $9(10,11)$ \\
\hline Propensão a gostar de algo com que está acostumado & $4(12,90)$ & $3(8,82)$ & $1(4,76)$ & $8(8,98)$ \\
\hline O edifício possui valor histórico e cultural & $4(12,90)$ & $3(8,82)$ & $1(4,76)$ & $8(8,98)$ \\
\hline O entrevistado possui ligação afetiva com o edifício & $1(3,22)$ & $6(17,64)$ & $0(00,00)$ & $7(7,86)$ \\
\hline O edifício possui importância no contexto urbano & $2(6,45)$ & $3(8,82)$ & $1(4,76)$ & $6(6,74)$ \\
\hline Preferência devido à vivência pessoal e urbana & $4(12,90)$ & $0(00,00)$ & $1(4,76)$ & $5(5,61)$ \\
\hline O edifício gera sensação de conforto & $2(6,45)$ & $3(8,82)$ & $0(00,00)$ & $5(5,61)$ \\
\hline Preferência por aspectos compositivos & $0(00,00)$ & $1(2,9)$ & $4(16,66)$ & $5(5,61)$ \\
\hline Influência de prejulgamento referente a edifício conhecido & $1(3,22)$ & $3(8,82)$ & $0(00,00)$ & $4(4,49)$ \\
\hline O respondente frequenta o edifício & $0(00,00)$ & $3(8,82)$ & $0(00,00)$ & $3(3,37)$ \\
\hline Tendência de rejeição ao novo & $2(6,45)$ & $0(00,00)$ & $0(00,00)$ & $2(2,24)$ \\
\hline O respondente preferiu o edifício por suas formas curvas & $1(3,22)$ & $1(2,9)$ & $0(00,00)$ & $2(2,24)$ \\
\hline O edifício remete a uma época & $1(3,22)$ & $0(00,00)$ & $1(4,76)$ & $2(2,24)$ \\
\hline Conhecimento da forma espacial do edifício & $0(00,00)$ & $2(5,88)$ & $0(00,00)$ & $2(2,24)$ \\
\hline \multicolumn{5}{|c|}{ Justificativas relacionadas ao valor histórico } \\
\hline Justificativas daqueles afetados pelo valor histórico & 19(100) & $50(100)$ & 34(100) & 103(100) \\
\hline Preferência por aspectos compositivos & $2(10,52)$ & $20(40,00)$ & $13(38,23)$ & $34(33,00)$ \\
\hline O valor histórico deve ser considerado & $3(15,78)$ & $4(8,00)$ & $1(2,94)$ & $8(7,76)$ \\
\hline O respondente atribui a lembranças a predileção pelo edifício & $1(5,26)$ & $4(8,00)$ & $0(00,00)$ & $5(4,85)$ \\
\hline O edifício é parte do cenário cotidiano & $1(5,26)$ & $0(00,00)$ & $3(8,82)$ & $4(3,88)$ \\
\hline Propensão a gostar de algo com que está acostumado & $2(10,52)$ & $2(4,00)$ & $0(00,00)$ & $4(3,88)$ \\
\hline Ser antigo agrega valor ao edifício & $1(5,26)$ & $3(6,00)$ & $0(00,00)$ & $4(3,88)$ \\
\hline Edifícios históricos deveriam ser preservados & $0(00,00)$ & $1(2,00)$ & $3(8,82)$ & $4(3,88)$ \\
\hline O edifício tem importância para o contexto urbano & $2(10,52)$ & $0(00,00)$ & $1(2,94)$ & $3(2,91)$ \\
\hline O estilo arquitetônico do edifício agradou & $1(5,26)$ & $2(2,00)$ & $0(00,00)$ & $3(2,91)$ \\
\hline Reconhecimento do Mercado Público & $0(00,00)$ & $1(2,00)$ & $2(5,88)$ & $3(2,91)$ \\
\hline Ser histórico afetou negativamente & $0(00,00)$ & $1(2,00)$ & $2(5,88)$ & $3(2,91)$ \\
\hline O edifício representa a preservação da cultura local & $1(5,26)$ & $1(2,00)$ & $0(00,00)$ & $2(1,94)$ \\
\hline O edifício remete à tradição e identidade local & $1(5,26)$ & $1(2,00)$ & $0(00,00)$ & $2(1,94)$ \\
\hline O edifício é representativo & $2(10,52)$ & $0(00,00)$ & $0(00,00)$ & $2(1,94)$ \\
\hline O respondente se identifica com o edifício & $1(5,26)$ & $1(2,00)$ & $0(00,00)$ & $2(1,94)$ \\
\hline Edifícios históricos remetem à humanização & $0(00,00)$ & $2(4,00)$ & $0(00,00)$ & $2(1,94)$ \\
\hline O edifício valoriza uma época & $0(00,00)$ & $2(4,00)$ & $0(00,00)$ & $2(1,94)$ \\
\hline
\end{tabular}

Nota: são apresentadas as justificativas mencionadas, pelo menos, por 2 dos 89 entrevistados; $\mathrm{N}$ arq c f sup= não arquitetos com formação superior; Resp s f sup= respondentes sem formação superior; Total= total da amostra de 180 respondentes; n.a (\%)= número absoluto de entrevistados que mencionaram a justificativa em questão (porcentagem de entrevistados em relação às amostras individuais ou total de entrevistados cujas avaliações foram afetadas pela familiaridade e valor histórico); os entrevistados podem ter mencionado mais de uma justificativa.

\section{Composição arquitetônica e qualidade estética: nível e tipo de formação}

A análise da relação entre composição arquitetônica e qualidade estética, considerando possíveis efeitos gerados pelo nível e tipo de formação, é realizada através do teste estatístico Kruskal-Wallis, onde a existência ou não de diferenças significativas entre as avaliações estéticas dos seis edifícios pelos três grupos é identificada. Assim, a existência de diferenças estatisticamente significativas quanto às avaliações estéticas dos edifícios entre os arquitetos, não arquitetos com formação universitária e aqueles sem formação universitária foi encontrada em relação a três dos seis edifícios:

(a) Edifício 1 (Figura 3 - edifício histórico com desordem; Kruskal-Wallis, $\chi^{2}=8,269$, sig.=0,016) (Tabela 1); 
(b) Edifício 4 (Figura 6 - edifício contemporâneo com desordem; Kruskal-Wallis, $\chi^{2}=9,074$, sig.= 0,011); e

(c) Edifício 5 (Figura 7 - edifício contemporâneo com ordem e estímulo; Kruskal-Wallis, $\chi^{2}=$ 35,873 , sig.=0,000).

A avaliação estética negativa do edifício 1 (edifício histórico com desordem) foi preponderante entre os arquitetos (45\%), enquanto a avaliação positiva foi predominante entre os não arquitetos com formação universitária $(41,6 \%)$ e entre aqueles sem formação universitária (45\%). Entretanto, além do fato de essas avaliações positivas não serem expressivas, parte não desprezível de não arquitetos formados $(28,3 \%)$ e daqueles sem formação universitária $(21,6 \%)$ também avaliou negativamente a edificação 1 (Tabela 1). A avaliação estética negativa do edifício 4 (edifício contemporâneo com desordem) foi preponderante entre os arquitetos $(38,3 \%)$ e entre os não arquitetos com formação universitária $(56,6 \%)$, enquanto a avaliação positiva foi predominante entre aqueles sem formação universitária (41,7\%). Todavia, além de essa avaliação ser pouco significativa, quase um terço destes respondentes $(28,3 \%)$ avaliou negativamente a edificação 4 (Tabela 1). A avaliação estética positiva do edifício 5 (edifício contemporâneo com ordem e estímulo) foi predominante para os três grupos: arquitetos $(78,3 \%)$; não arquitetos formados $(36,6 \%)$; e respondentes sem formação $(33,3 \%)$. Entretanto, as avaliações negativas foram expressivas nestes dois últimos grupos, respectivamente $33,4 \%$ e $31,7 \%$ (Tabela 1).

Assim, essas diferenças revelam uma maior valorização estética da ideia de ordem e uma maior desvalorização da ideia de desordem pelos arquitetos do que pelos outros dois grupos, que tendem a uma maior valorização do estímulo visual. Por outro lado, o fato de não terem sido encontradas diferenças significativas em relação às avaliações estéticas das outras três edificações mostra a similaridade nas avaliações dos três grupos. Ainda, quando uma edificação apresenta uma organização e estímulo visual evidentes, ela tende a ser avaliada positivamente, tal como o foi a edificação 3 (Figura 5 - edifício histórico com ordem e estímulo), a mais bem avaliada pelos três grupos (Tabela 1).

Diferenças estatisticamente significativas quanto às ordens de preferência pelos edifícios entre os arquitetos, não arquitetos com formação universitária e aqueles sem formação universitária foram encontradas em relação aos mesmos três edifícios para os quais foram encontradas diferenças nas avaliações, com adição do edifício 3 (Tabela 2):

(a) Edifício 1 (Figura 3 - edifício histórico com desordem; Kruskal-Wallis, $\chi^{2}=9,787$, sig.= 0,007);

(b) Edifício 3 (Figura 5 - edifício histórico com ordem e estímulo; Kruskal-Wallis, $\chi^{2}=10,088$, sig.=0,006);

(c) Edifício 4 (Figura 6 - edifício contemporâneo com desordem; Kruskal-Wallis, $\chi^{2}=9,608$, sig.= 0,008); e

(d) Edifício 5 (Figura 7 - edifício contemporâneo com ordem e estímulo; Kruskal-Wallis, $\chi^{2}=$ 36,627, sig. $=0,000)$.

O edifício 1 foi o última na preferência dos arquitetos e o terceiro na preferência dos outros dois grupos (Tabela 2). Embora tenha sido encontrada uma diferença estatisticamente significativa (em função da pontuação recebida Tabela 2), o edifício 3 foi o mais preferido pelos três grupos. O edifício 4 foi o penúltimo na preferência dos arquitetos e o último na preferência dos outros dois grupos. O edifício 5 foi o segundo na preferência dos arquitetos e o quarto na preferência dos outros dois grupos. Esses resultados, obtidos pelas comparações entre os seis edifícios, tendem a reforçar os anteriores, relativos às avaliações individuais destes edifícios, salientando-se que, quando existentes, prevalecem as diferenças entre o grupo de arquitetos e os outros dois grupos (para os quais a ordem de preferência dos seis edifícios foi a mesma). Embora não tenham sido encontradas diferenças estatisticamente significativas, o edifício 2 foi $o$ terceiro preferido pelos arquitetos e o segundo preferido pelos outros dois grupos, e o edifício 6 foi o quarto preferido pelos arquitetos e o quinto preferido pelos outros dois grupos (Tabela 2).

A ordem de preferência pelos arquitetos (Tabela 2) reforça a prioridade da ideia de ordem e estímulo (edifícios 3 [Figura 5] e 5 [Figura 7]), seguida da ordem e pouco estímulo (edifícios 2 [Figura 4] e 6 [Figura 8]), e, por último, a ideia de desordem representada pelos edifícios 4 (Figura 6) e 1 (Figura 3). Para os outros dois grupos, embora a maior preferência também tenha sido por uma edificação com ordem e estímulo (Edifício 3, Figura 5) e a menor preferência por uma edificação com desordem (Edifício 4, Figura 6), uma edificação com desordem (Edifício 1, Figura 3) foi levemente preferida a uma edificação com ordem e estímulo (Edifício 5, Figura 7) e a uma com ordem e pouco estímulo (Edifício 6, Figura 8) (Tabela 2). A explicação parece estar no maior estímulo gerado pelo Edifício 1 (Figura 3) em comparação 
aos gerados pelos outros dois (Figuras 7 e 8), devido às cores e detalhes, além do maior contraste entre as cores do Edifício 1 e o fundo branco da Prancha 1 (Figura 1) do que entre as cores dos Edifícios 7 e 8 e o fundo branco da Prancha 2 (Figura 2). Ainda, a "existência de estímulo visual" foi, claramente, a principal justificativa apresentada pelos não arquitetos com formação universitária e por aqueles sem tal formação para o edifício mais preferido, enquanto para os arquitetos a principal justificativa foi a "relação ordenada" (Tabela 3). Nesse sentido, enquanto os arquitetos apresentaram a "relação desordenada" como a principal justificativa para o edifício menos preferido, os outros dois grupos mencionaram a "falta de estímulo visual", principalmente aqueles sem formação universitária, com as diferenças nessas justificativas e nas anteriores tendendo a ser estatisticamente significativas (Tabela 3). Esses resultados corroboram os anteriores com relação à maior valorização da ideia de ordem e maior desvalorização da ideia de desordem pelos arquitetos, e da maior valorização da existência de estímulo visual pelos outros dois grupos. Por outro lado, quando a edificação agrega ordem e estímulo visual, tal como o edifício 3 (Figura 5), passa a ser a mais preferida, independentemente no nível e do tipo de formação de quem a avalia (Tabela 3).

\section{Conclusão}

A análise da relação entre composição arquitetônica e qualidade estética, considerando os pressupostos da estética filosófica e da estética empírica, revela que composições arquitetônicas caracterizadas por distintos níveis de ordem e estímulo visual foram avaliadas diferentemente, indicando qualidades estéticas heterogêneas. Identificou-se uma clara tendência de avaliações positivas estarem associadas à ideia de ordem e estímulo (como evidenciado pelas avaliações do edifício 3) e de avaliações negativas estarem associadas à ideia de desordem (como evidenciado pelas avaliações do edifício 4). Composições caracterizadas por ordem e pouco estímulo tendem a oscilar entre positivo e negativo (como evidenciado pelas avaliações dos edifícios 2 e 6). Esses resultados relativos às avaliações individuais dos edifícios foram corroborados pelas ordens de preferências dessas edificações pelos respondentes. As justificativas apresentadas pelos respondentes evidenciam a importância da ideia de ordem e estímulo visual para uma composição arquitetônica esteticamente qualificada, assim como sustentam o impacto negativo provocado pela falta de organização e de estímulo. Foi possível, portanto, identificar no objeto observado e avaliado características formais que explicam tais avaliações. Logo, o pressuposto da estética empírica (a beleza está mais no que é observado), que procura explicar as avaliações estéticas positivas e negativas (LANG, 1987), prevaleceu sobre o pressuposto da estética filosófica (a beleza está nos olhos de quem vê), para a qual tais explicações são improcedentes, conforme argumentado por Ruskin (1885 ${ }^{3}$ apud LANG, 1987). O fato de as avaliações estéticas terem sido validadas através da identificação de regularidades entre as respostas das pessoas e das explicações baseadas nas características dos elementos avaliados, indica um suporte para a abordagem adotada pela estética empírica e uma rejeição da abordagem adotada pela estética filosófica. Esses resultados corroboram aqueles obtidos em avaliações de nove cenas urbanas por esses mesmos respondentes, tais como o impacto estético positivo da ideia de ordem e estímulo visual, e a tendência do impacto estético negativo da ideia de desordem (REIS; BIAVATTI; PEREIRA, 2011). Tais resultados também são sustentados pela preferência por duas cenas ordenadas em detrimento de uma cena desordenada, em investigação realizada com três cenas urbanas (KOWARICK et al., 2008), e por resultados anteriores sobre a necessidade de ordem na relação entre os elementos arquitetônicos (p.ex., WEBER, 1995).

A análise do papel da estética formal e da estética simbólica em explicar a qualidade estética de uma composição arquitetônica, através de possíveis impactos gerados pelas ideias de familiaridade e valor histórico, sugere que a percepção de uma edificação como familiar teve apenas alguma tendência a afetar positivamente a preferência pela edificação. Esses resultados guardam certa sintonia com aqueles obtidos através da avaliação de nove cenas urbanas, onde um maior nível de familiaridade com a cena não foi determinante para sua avaliação positiva (REIS; BIAVATTI; PEREIRA, 2011), conforme também mencionado por NASAR (1998). Por outro lado, parece que o papel menos determinante da familiaridade na avaliação de edificações individuais e de cenas com edificações não se reproduz em preferências por distintas paisagens naturais, onde a familiaridade com tais paisagens foi bem mais determinante nas preferências pelas mesmas, conforme estudos interculturais realizados (FALK; BALLING, 2010).

Embora a percepção de valor histórico da edificação tenha sido mencionada pela maioria dos respondentes como tendo afetado suas avaliações

\footnotetext{
${ }^{3}$ RUSKIN, J. Works. New York: John Wiley, 1885.
} 
estéticas, as justificativas apresentadas revelam que os aspectos compositivos do edifício, seus atributos formais e não simbólicos, é que realmente afetaram suas avaliações. Ainda, os arquitetos, aqueles com maior conhecimento de história da arquitetura devido a sua formação acadêmica (e, logo, do valor histórico de uma edificação), entenderam, majoritariamente, que a percepção de valor histórico não foi relevante para a avaliação estética do edifício. O predomínio dos aspectos formais sobre os simbólicos também ficou evidenciado pelas avaliações positivas mais expressivas dos dois edifícios com ordem e estímulo (edifício 3 - histórico; edifício 5 contemporâneo) pelos arquitetos. Esses resultados são corroborados por aqueles obtidos na avaliação de nove cenas urbanas, onde a existência de valor histórico também não foi determinante para uma avaliação mais positiva ou uma maior preferência pela cena (REIS; BIAVATTI; PEREIRA, 2011), e vão ao encontro da ideia de que as pessoas podem avaliar edificações e cenas históricas positivamente devido à existência de ordem e variedade (estímulo) (NASAR, 1998). Assim, embora "[...] preferências por cenas com habitações podem estar relacionadas à variáveis que carregam características formais e associativas que sejam desejáveis [...]" (NASAR, 1992b, p. 288), as avaliações realizadas sustentam o predomínio da estética formal sobre a estética simbólica em explicar os resultados obtidos.

A análise da relação entre composição arquitetônica e qualidade estética, considerando possíveis efeitos gerados pelo nível e tipo de formação, revelou maior valorização estética da ideia de ordem e maior desvalorização da ideia de desordem pelos arquitetos do que pelos outros dois grupos, que tendem a uma maior valorização do estímulo visual. Estes resultados são sustentados pelas ordens de preferências dos edifícios, salientando-se que, quando existentes, prevalecem as diferenças entre o grupo de arquitetos e os outros dois grupos. A maior valorização estética da ideia de ordem e a maior desvalorização da ideia de desordem por parte dos arquitetos, em comparação ao grupo dos não arquitetos com formação universitária e ao grupo daqueles sem formação universitária, que parecem necessitar de um nível maior de estímulo visual, também foram encontradas no estudo realizado sobre as nove cenas urbanas (REIS; BIAVATTI; PEREIRA, 2011). Ainda, a valorização da ideia de ordem pelos arquitetos e da ideia de estímulo visual pelos não arquitetos com formação e por aqueles sem formação universitária são similares aos resultados obtidos por John (2012) em sua investigação sobre a estética do mobiliário urbano. Assim, podem ser explicadas as diferenças encontradas entre as avaliações estéticas por arquitetos e leigos com formação, de edificações mais contemporâneas (diferenciadas, com estilos mais avançados) e de edificações mais convencionais (populares, com estilos mais tradicionais), em vários estudos realizados (DEVLIN; NASAR, 1989; NASAR, 1998; UZZEL; JONES, 2000). O fato de os leigos preferirem as edificações com estilo mais tradicional parece estar no maior estímulo visual gerado por elas, devido, por exemplo, ao maior nível de detalhes existentes em comparação a edificações mais contemporâneas, como aquelas do movimento moderno. Nesse sentido, Nasar (1998, p. 19) atesta que: "Exames das reações públicas à arquitetura moderna, mesmo depois de mais de 60 anos, indicam um desgosto pela forma (NASAR, 1994 $\left.{ }^{4}\right) . "$ Entretanto, não significa que a ideia de "desordem" tenha sido aceita pelos dois grupos de não arquitetos, conforme já revelado nas avaliações de cenas urbanas por esses mesmos três grupos (REIS; BIAVATTI; PEREIRA, 2011). Adicionalmente, sustentam esses resultados aqueles obtidos na avaliação de três cenas urbanas onde a cena com desordem foi preterida em prol das duas cenas com ordem, não somente pelos arquitetos, mas também pelos não arquitetos (KOWARICK et al., 2008).

Contudo, quando a edificação apresenta uma organização e estímulo visual evidentes (tal como o edifício 3), ela tende a ser avaliada positivamente, de maneira expressiva, independentemente do nível e do tipo de formação, corroborando os resultados encontrados nas avaliações de nove cenas urbanas (REIS; BIAVATTI; PEREIRA, 2011). Logo, estes resultados não sustentam a afirmação de que os arquitetos possuem preferências por edificações distintas das do público (DEVLIN; NASAR, 1989; FAWCETT; ELLINGHAM; PLATT, 2008; NASAR, 1998), de que as preferências visuais dos arquitetos diferem das dos demais usuários, de que as preferências distintas dos arquitetos são sustentadas por uma educação especializada (FAWCETT; ELLINGHAM; PLATT, 2008). Nesse sentido, arquitetos e não arquitetos tiveram uma percepção similar da aparência geral do centro de Porto Alegre (KOWARICK et al., 2008). Assim, os argumentos de Nasar (1998, p. 32) mencionados a seguir não são corroborados pelos resultados das avaliações das seis edificações:

${ }^{4}$ NASAR, J. Urban Design Aesthetics: the evaluative qualities of building exteriors. Environment and Behavior, Thousand Oaks, v. 26, n. 3, p. 377-401, 1994. 
[...] percepções de características formais dependem do conteúdo [significado das formas] [...];

Os julgamentos objetivos das características formais [de uma edificação] dependem do reconhecimento e compreensão dos estilos por cada grupo [arquitetos e pessoas sem formação em arquitetura] [...].

[...] julgamentos de ordem podem depender do entendimento do observador da categoria conteúdo [esta categoria se refere aos aspectos simbólicos, aos significados da forma].

Os resultados das avaliações das seis edificações reforçam a ideia de que edificações caracterizadas por ordem e estímulo constituem, potencialmente, composições arquitetônicas com qualidade estética, e, logo, espaços urbanos e cidades com qualidade estética. Esses resultados são sustentados por aqueles relativos às avaliações de nove cenas urbanas, onde a cena de Praga foi considerada muito satisfatória, sendo a mais bem avaliada, em função da presença de ordem e estímulo visual, e não de seu conteúdo, já que, pelo menos, os respondentes sem formação em arquitetura (dois terços da amostra) não apresentavam o potencial de conhecer o conteúdo e/ou o significado das edificações que constituíam tal cena (REIS; BIAVATTI; PEREIRA, 2011).

Portanto, os resultados obtidos evidenciam a possibilidade de explicar as reações das pessoas com relação à estética da arquitetura e reforçam a ideia de que é possível projetar de maneira que a composição adotada apresente o potencial de ser avaliada positivamente em termos estéticos por pessoas com diferentes níveis e tipos de formação, prevalecendo os aspectos formais e não simbólicos, e indo ao encontro do argumentado por Weber (1995) de que a forma arquitetônica pode ser percebida livre de significado. A procura por uma composição arquitetônica com qualidade estética deixa de ser resultado simplesmente de mimetizações ou de explorações não fundamentadas, para vir a ser fundamentada nas ideias de ordem e estímulo visual, com base no processo de percepção visual. Isaacs (2000, p. 147) menciona:
Gombrich $\left(1984^{5}\right)$ explica que ordem é fácil de perceber e lembrar, mas pode se tornar monótona, mesmo percebida automaticamente. Entretanto, ruptura $e$ variação excitam a mente. Portanto, estética é um balanço entre ordem $e$ confusão $[\mathrm{Ou}$ melhor, entre ordem e estímulo].

Contudo, novas pesquisas são necessárias para aprofundar o conhecimento existente, incluindo uma maior diversidade de exemplares arquitetônicos e distintos contextos socioculturais. Também existe a necessidade de quantificar e testar a importância, para distintos grupos de pessoas, de conceitos relacionados à ideia de ordem (HASSE; WEBER, 2010; REIS, 2002a), numa linha de investigação já salientada por Stevens (1990, p. 18):

O problema central da teoria arquitetônica é determinar os princípios abstratos que estabelecem a forma arquitetônica. Uma vez descobertos, acredita-se, estes princípios capacitarão então os arquitetos a projetar boa arquitetura".

Futuras investigações também podem incluir o exame das relações entre níveis de familiaridade e grau de satisfação estética com edificações e paisagens naturais, assim como entre nível de organização e estímulo visual de edificações modernas e níveis de satisfação estética. Com base nos resultados encontrados, pode-se inferir, por exemplo, que o "Itamaraty" (Figura 13) apresenta um nível de estímulo visual, gerado pelos contrastes entre cheios e vazios, transparências e opacidades, colunas e planos, bem superior ao Munson-Williams-Proctor Institute (Figura 14) e, logo, parece gerar maior satisfação estética, que necessita, contudo, de sustentação empírica.

\footnotetext{
${ }^{5}$ GOMBRICH, E.H. The Sense of Order. London: Phaidon, 1984.
} 
Figura 13 - Palácio do Itamaraty, Oscar Niemeyer, 1962

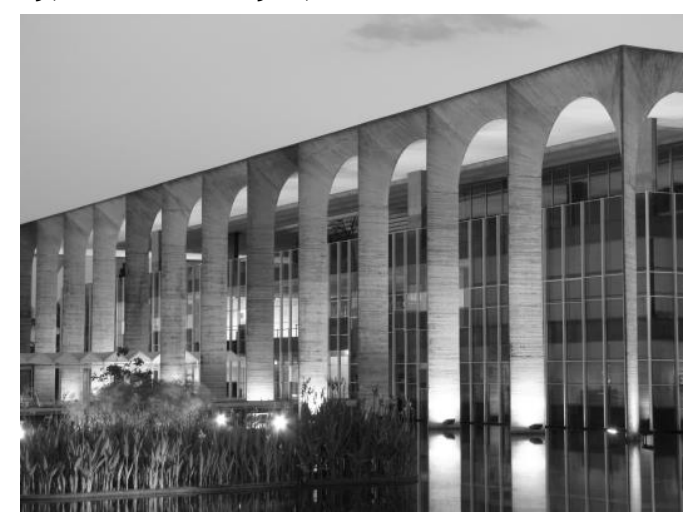

Figura 14 - Munson-Williams-Proctor Institute, Utica, New York, Philip Johnson, 1960

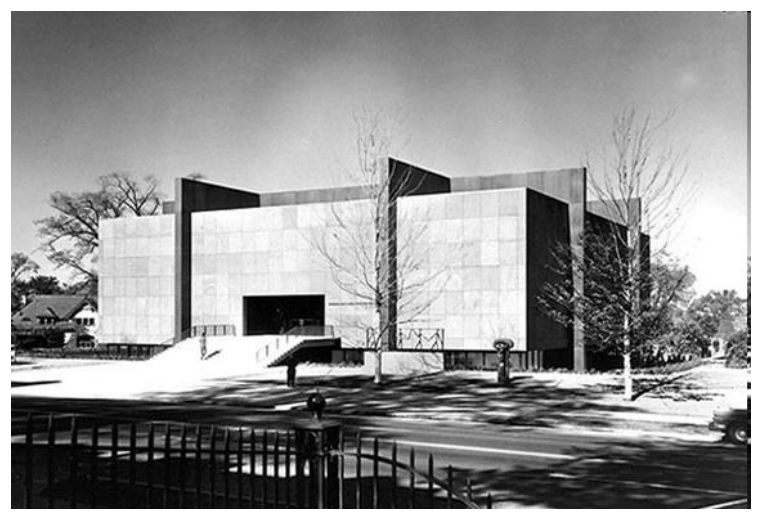

Fonte: <http://www.pjar.com/project_page_munson_williams_image1.html>.

Concluindo, espera-se que os resultados e as reflexões apresentadas neste artigo, além de contribuírem para novas pesquisas, tenham implicações tanto para a prática profissional do arquiteto quanto para o ensino da arquitetura, auxiliando na realização de composições arquitetônicas esteticamente qualificadas. A importância da qualidade estética das edificações está no efeito gerado não somente para seus usuários mas também para os demais usuários da cidade, já que o conjunto das edificações afeta o desempenho urbano e a qualidade de vida dos cidadãos.

\section{Referências}

AMEDEO, D. External and Internal Information in Versions of Scenic-Quality Perceptions. Journal of Architectural and Planning Research, Chicago, v. 16, n. 4, p. 328-352, 1999.

COOPER MARCUS, C.; SARKISSIAN, W. Housing as if People Mattered. Berkeley: University of California Press, 1986.
DEVLIN, K.; NASAR, J. L. The Beauty and the Beast: some preliminary comparisons of "high" versus "popular" residential architecture and public versus architect judgments of same. Journal of Environmental Psychology, Exeter, v. 9, p. 333-344, 1989.

FALK, J. H.; BALLING, J. D. Evolutionary Influence on Human Landscape Preference. Environment and Behavior, Thousand Oaks, v. 42, n. 4, 479-493, jun. 2010.

FAWCETT, W.; ELLINGHAM, I.; PLATT, S. Reconciling the Architectural Preferences of Architects and the Public: the ordered preference model. Environment and Behavior, Thousand Oaks, v. 40, n. 5, p. 599-618, sep. 2008.

GIFFORD, R. et al. Decoding Modern Architecture: a lens model approach for understanding the aesthetic differences of architects and laypersons. Environment and Behavior, Thousand Oaks, v. 32, n. 2, p. 163-187, mar. 2000. 
HASSE, C.; WEBER, R. Visual Balance of Facades: investigating the interplay between eye movements and balance judgments. In: INTERNATIONAL ASSOCIATION OF EMPIRICAL AESTHETICS CONGRESS, 21., Dresden, 2010. Proceedings... Dresden: IAEA, 2010.

HERZOG, T. R. A Cognitive Analysis of Preference For Urban Spaces. Journal of Environmental Psychology, Exeter, v. 12, n. 3, p. 237-248, 1992.

HERZOG, T. R.; KAPLAN, S.; KAPLAN, R. The Prediction of Preference For Familiar Urban Places. Environment and Behavior, Thousand Oaks, v. 8, n. 4, p. 627-456, 1976.

HERZOG, T. R.; SHIER, R. Complexity, Age, and Building Preference. Environment and Behavior, Thousand Oaks, v. 32, n. 4, p. 557-575, 2000.

ISAACS, R. The Urban Picturesque: an aesthetic experience of urban pedestrian places. Journal of Urban Design, Florence, v. 5, n. 2, p. 145-180, jun. 2000 .

JACOBS, J. Morte e Vida das Grandes Cidades. São Paulo: Martins Fontes, 2000.

JEFFREY, D.; REYNOLDS, G. Planners, Architects, the Public, and Aesthetics Factor Analysis of Preferences For Infill Developments. Journal of Architectural and Planning Research, Chicago, v. 16, n. 4, p. 271-288, winter 1999.

JOHN, N. Avaliação Estética do Mobiliário Urbano e do Uso de Abrigos de Ônibus Por Cadeirantes. Porto Alegre, 2012. 209 f.

Dissertação (Mestrado em Planejamento Urbano e Regional) - Programa de Pós-Graduação em Planejamento Urbano e Regional, Faculdade de Arquitetura, Universidade Federal do Rio Grande do Sul, Porto Alegre, 2012.

KAPLAN, R.; KAPLAN, S.; RYAN, R. With People in Mind: design and management of everyday nature. Washington: Island, 1998.

KOWARICK, A. et al. Estética Urbana: uma análise no centro de Porto Alegre. In: ENCONTRO NACIONAL DE TECNOLOGIA DO AMBIENTE CONSTRUÍDO, 12., Fortaleza, 2008. Anais... Porto Alegre: UFC; ANTAC, 2008.

LANG, J. Creating Architectural Theory: the role of the behavioural sciences in environmental design. New York: Van Nostrand Reinhold, 1987.

LAY, M. C.; REIS, A. Análise Quantitativa na Área de Estudos Ambiente-Comportamento. Ambiente Construído, Porto Alegre, v. 5, n. 2, p. 21-36, abr./jun. 2005.
MEGAHED, Y. S.; GABR, H. S. Quantitative Architectural Aesthetics Assessment: applying Birkhoff's aesthetic measure in architecture. In: INTERNATIONAL ASSOCIATION OF EMPIRICAL AESTHETICS CONGRESS, 21., Dresden, 2010. Proceedings... Dresden: IAEA, 2010.

NASAR, J. The Evaluative Image of the City. Thousand Oaks: SAGE, 1998.

NASAR, J. New Developments in Aesthetics for Urban Design. In: MOORE, G.; MARANS, R. (Eds.). Advances in Environment, Behavior, and Design: Toward the Integration of Theory, Methods, Research, and Utilization. Cambridge: Cambridge University Press, 1997. p. 149-193.

NASAR, J. (Ed.). Environmental Aesthetics: theory, research, and applications. Cambridge: Cambridge University Press, 1992a.

NASAR, J. Perception and Evaluation of Residential Street Scenes. In: NASAR, J. (Ed.). Environmental Aesthetics: theory, research, and applications. Cambridge: Cambridge University Press, 1992b. p. 275-289.

PORTEOUS, J. D. Environmental Aesthetics: ideas, politics and planning. London: Routledge, 1996.

PRAK, N. The visual Perception of the Built Environment. Delft: Delft University Press, 1985.

REIS, A. Repertório, Análise e Síntese: uma introdução ao projeto arquitetônico. Porto Alegre: Editora da UFRGS, 2002a. v. 1. p. 231.

REIS, A. Aparência, Qualidade e Habitação Sustentável. In: ENCONTRO NACIONAL DE TECNOLOGIA DO AMBIENTE CONSTRUÍDO, 9., Foz do Iguaçu, 2002. Anais... Porto Alegre: ANTAC, 2002b. p. 1105-1112.

REIS, A. Mass Housing Design, User

Participation and Satisfaction. Oxford, 1992. 361 f. Tese (Doctor of Philosophy in Architecture) Post-graduate Research School, School of Architecture, Oxford Brookes University, Oxford, 1992.

REIS, A.; LAY, M.C. Avaliação da Qualidade de Projetos: uma abordagem perceptiva e cognitiva. Ambiente Construído, Porto Alegre, v. 6, n. 3, p. 21-34, jul./set. 2006.

REIS, A.; LAY, M. C. Habitação de Interesse Social: uma análise estética. Ambiente Construído, Porto Alegre, v. 3, n. 4, p. 7-19, out./dez. 2003. 
REIS, A.; LAY, M.C. As Técnicas de APO Como Instrumento de Análise Ergonômica do Ambiente Construído - Curso Avaliação Pós-Ocupação. In: ENCONTRO NACIONAL e I ENCONTRO LATINO-AMERICANO DE CONFORTO NO AMBIENTE CONSTRUÍDO, 3., Gramado, 1995. Anais... Porto Alegre: ANTAC, 1995.

REIS, A.; BIAVATTI, C.; PEREIRA, M. L. Estética Urbana: uma análise através das ideias de ordem, estímulo visual, valor histórico e familiaridade. Ambiente Construído, Porto Alegre, v. 11, n. 4, p. 185-204, out./dez. 2011.

SANOFF, H. Visual Research Methods in Design. New York, Van Nostrand Reinhold, 1991.

STAMPS, A. Psychology and the Aesthetics of the Built Environment. Massachusetts: KAP, 2000 .

STEVENS, G. The Reasoning Architect: mathematics and science in design. New York: McGraw-Hill Publishing Company, 1990.
UZZEL, D.; JONES, E. The Development of a Process-Based Methodology For Assessing the Visual Impact of Buildings. Journal of Architectural and Planning Research, Chicago, v. 17 , n. 4 , p. $330-343,2000$.

VON MEISS, P. Elements of Architecture: from form to place. London: E \& FN Spon, 1993.

WEBER, R. On the Aesthetics of Architecture: a psychological approach to the structure and the order of perceived architectural space. Aldershot: Avebury, 1995.

WHYTE, W. City: rediscovering the center. New York: Anchor Books, 1990.

\section{Agradecimentos}

Além dos agradecimentos ao $\mathrm{CNPq}$ e à FAPERGS, pelo apoio financeiro para a realização desta pesquisa, agradecimentos são prestados à RS Projetos, pelas fotografias cedidas, ao IPHAN, IPHAE e EPAHC, pela lista das edificações tombadas, e aos docentes e funcionários da UFRGS, assim como aos arquitetos de outras instituições e escritórios privados que participaram desta pesquisa.

Antônio Tarcísio da Luz Reis

Faculdade de Arquitetura | Universidade Federal do Rio Grande do Sul | Rua Sarmento Leite, 320, Centro | Porto Alegre - RS - Brasil | CEP 90050-170 | Tel.: (51) 3308-4529 | E-mail: tarcisio@orion.ufrgs.br

Camila Damiani Biavatti

Faculdade de Arquitetura | Universidade Federal do Rio Grande do Sul | E-mail: camila_biavatti@hotmail.com

Maria Lourdes Pereira

Faculdade de Arquitetura | Universidade Federal do Rio Grande do Sul | E-mail: mlseadi@hotmail.com

Revista Ambiente Construído

Associação Nacional de Tecnologia do Ambiente Construído

Av. Osvaldo Aranha, $99-3^{\circ}$ andar, Centro

Porto Alegre - RS - Brasil CEP 90035-190

Telefone: +55 (51) 3308-4084

Fax: +55 (51) 3308-4054

www.seer.ufrgs.br/ambienteconstruido

E-mail: ambienteconstruido@ufrgs.br 